\title{
Nutrient remobilization during development and senescence of Petunia x hybrida floral organs
}

\author{
Karyn L. Smith \\ West Virginia University
}

Follow this and additional works at: https://researchrepository.wvu.edu/etd

\section{Recommended Citation}

Smith, Karyn L., "Nutrient remobilization during development and senescence of Petunia $\mathrm{x}$ hybrida floral organs" (2004). Graduate Theses, Dissertations, and Problem Reports. 2016.

https://researchrepository.wvu.edu/etd/2016

This Thesis is protected by copyright and/or related rights. It has been brought to you by the The Research Repository @ WVU with permission from the rights-holder(s). You are free to use this Thesis in any way that is permitted by the copyright and related rights legislation that applies to your use. For other uses you must obtain permission from the rights-holder(s) directly, unless additional rights are indicated by a Creative Commons license in the record and/ or on the work itself. This Thesis has been accepted for inclusion in WVU Graduate Theses, Dissertations, and Problem Reports collection by an authorized administrator of The Research Repository @ WVU. For more information, please contact researchrepository@mail.wvu.edu. 


\title{
Nutrient Remobilization During Development and Senescence of Petunia x hybrida Floral Organs
}

\author{
Karyn L. Smith
}

Thesis submitted to the Davis College of Agriculture, Forestry, and Consumer Sciences at

West Virginia University in partial

fulfillment of the requirements

for the degree of

Master of Science
in
Horticulture

Sven Verlinden, Ph.D., Chair Todd West, Ph.D.

John Balasko, Ph.D.

Department of Horticulture

Morgantown, West Virginia

2004

Keywords: Flower Senescence, Ethylene, Nutrients, Cytokinin, Remobilization, Pollination 


\title{
ABSTRACT \\ Nutrient Remobilization During Development and Senescence of Petunia x hybrida Floral Organs
}

\author{
Karyn L. Smith
}

Fresh weight, dry weight, and macronutrient content of corollas, ovaries, and styles were measured during the development and senescence of several wild-type and transgenic Petunia x hybrida plants. Flowers of age-related senescence exhibited growth, maintenance, and senescence phases during development. Flowers terminated by pollination-induced senescence exhibited only growth and senescence phases. Fresh and dry weight of Mitchell, V26, and SAG12-IPT corollas followed patterns previously observed in climacteric flowers. SAG12-IPT, a cytokinin overproducing plant, exhibited a prolonged maintenance phase compared to V26. A temporary increase in fresh weight, dry weight, and macronutrients of Mitchell corollas occurred at the expected onset of the ethylene climacteric of the flowers. Increases in ovary fresh weight, dry weight, and select macronutrient contents were concomitant with decreases in these same measurements of corollas, although corolla remobilization contributed only small amounts to the growth of ovaries during age-related and pollination-induced senescence. 


\section{ACKNOWLEDGMENTS}

I would first like to extend my gratitude to Dr. Sven Verlinden and Dr. Barton Baker for giving me the opportunity to participate in this program in order to expand my knowledge of horticulture. I would also like to recognize Dr. Todd West and Dr. John Balasko for their contribution as committee members. Thanks to the staff at the WVU Greenhouse, particularly Susan Myers, for her encouragement and assistance throughout the research. Last, but not least, a tremendous thanks to my colleague, Mihaela Iordachescu, for her guidance, leadership, and support during my stay here at WVU. 


\section{TABLE OF CONTENTS}

I. CHAPTER ONE: Introduction................................. 1

\section{CHAPTER TWO: Age-Related Senescence}

Introduction..................................................... 18

Materials and Methods............................................p. 19

Results.................................................... 22

Discussion........................................................ 27

Graphs and Tables............................................. 33

\section{CHAPTER THREE: Pollination-Induced Senescence}

Introduction..................................................... 51

Materials and Methods......................................... p. 51

Results.................................................... 52

Discussion............................................... 54

Graphs and Tables............................................ 56

IV. Literature Cited............................................. p. 65 


\section{CHAPTER ONE: Introduction}

\section{Flower longevity}

Flowers are the structures responsible for sexual reproduction, and thus play a crucial role in the perpetuation of the earth's most abundant group of plants, the angiosperms (Rubinstein, 2000). Angiosperms, or flowering plants, dominate the landscape and are believed to have existed as early as 140 million years ago (Sun et al., 1998). Flower size can be as small and simple as those on the Wolffia plant or as large and complex as those of the odoriferous Titan Arums. The angiosperm flower is composed of several organs, each of which performs many different functions leading to successful reproduction, such as production of pollen, pollination, and the development and dispersal of viable seeds (Larsen et al., 1993).

Another important function of flowers is to attract pollinators. The initial attraction between flowers and their pollinators can be the result of corolla color and shape, whereas the end of a flower's attraction to pollinators may be due to alterations in these visible cues, such as permanent flower closure, corolla color change, and withering or abscission of the petals. Therefore, floral attraction may be reduced by pollination (van Doorn, 1997). For example, Petunia flowers attract nocturnal moths (Brantjes, 1973), because of their long, slender corolla tubes, heavy fragrance, and bright corolla colors that can easily be seen at night (Jones and Luchsinger, 1986). The subsequent wilting of the corolla, following pollination, can be considered as a functional means of communication between the flower and the environment. When the corolla has ceased to function and the pollinators are no longer attracted to this flower (Gilissen, 1977), they may seek out flowers that are still virgin (van Doorn, 1997). 
The opportunity for pollination depends on flower longevity, meaning the length of time that a flower remains open and functional (Ashman and Schoen, 1994). This length of time varies from species to species and even within cultivars of the same species (Stead, 1992), indicating that longevity is a genetically conserved, hereditary trait (Sparnaaij, 1976). For example, morning glory flowers live less than one day, whereas orchids may live for several weeks or months. Many flowers, such as orchids, have evolved elaborate corollas, which serve to attract pollinators and encourage reproduction. However, larger, more attractive petals require more resources for self-preservation (Ashman and Schoen, 1997). This concept can also be understood in terms of a costbenefit analysis: Flowers must remain open to facilitate ovule fertilization and pollen dissemination, which requires the use of costly resources, so when it becomes more beneficial for the plant to construct a new flower than to maintain an existing one, flower senescence occurs (Ashman and Schoen, 1994).

\section{Flower Senescence and Programmed Cell Death}

Senescence, on the whole plant level, can be broadly defined as a culmination of events leading to the death of cells, tissues, or organs (Reid, 1989). It is important, however, to distinguish between aging and senescence. Aging represents a passive degeneration that is a consequence of an accumulation of lesions that may decrease resistance to stress, thereby increasing the probability of death (Nooden and Leopold, 1988). Senescence represents endogenously controlled degenerative processes leading to certain death (Leopold, 1975). More specifically, senescence refers to those events that are part of a genetically based program leading to programmed cell death (PCD) (Rubinstein, 2000). 
Programmed Cell Death has previously been described as a “cell suicide” process that can be initiated by a variety of stimuli, such as environmental cues and developmental signals (Xu and Hanson, 2000). Programmed Cell Death is also part of the life cycle of animals, but is referred to as 'apoptosis' (Jacobson et al., 1997). In plants, PCD is and integral part of normal plant development, including senescence, root cap sloughing, and the abortion of floral organs (Xu and Hanson, 2000). Another important function of PCD is to remobilize as much nutrition as possible to benefit the whole plant and conserve costly resources (Smart, 1994).

One type of PCD, flower senescence, is a process that can be visibly recognized by morphological alterations such as petal wilting and color changes. Wilting is caused primarily by a loss of water content and solute concentration from the cells, thereby decreasing the cell's turgor pressure (Halevy and Mayak, 1981). This visible loss of turgor is the result of highly coordinated physiological and biochemical changes, such as the degradation of numerous cellular components, especially membranes. Changes in membranes that occur throughout flower development have been studied extensively (Adam et al., 1983; Borochov et al., 1984; Brown et al., 1987; Brown et al., 1991; Itzhaki et al., 1990; Borochov, 1995). Changes in cell membrane integrity, observed mostly in the very late stage of petal senescence, lead to a leakage of amino acids, sugars, $\mathrm{K}^{+}$, and total electrolytes from the flower petals (Borochov and Woodson, 1989; Rubinstein, 2000). In contrast to membrane integrity, changes in membrane composition occur during the earlier stage of petal senescence. A decline in membrane polar lipids has been shown in Ipomoea, Tradescantia, and carnations (Beutelmann and Kende, 1977; Suttle and Kende, 1980; Mayak et al., 1985). 
During flower senescence a loss of dry matter also occurs, due to the hydrolysis of macromolecules for respiration as well as the redistribution of carbon and nitrogen to other floral organs (Borochov and Woodson, 1989). Although proteins are degraded, the synthesis of new proteins is necessary for petal senescence (Suttle and Kende, 1980; Wulster et al., 1982; Woodson and Handa, 1987). An increase in RNase activity has also been associated with senescence (Wilson, 1982). It has been suggested that the role of RNase in senescence is to aid in the remobilization of phosphate (Wilson, 1982; Taylor et al., 1993). RNase activities have been shown to increase in senescing corollas of Petunia inflata, an ethylene-sensitive flower, and in the petals of daylily, an ethylene-insensitive flower (Panavas et al., 1998; Xu and Hanson, 2000).

\section{Ethylene}

Petunia flowers, among others, are classified as climacteric based on the presence of an increased rate of ethylene production during flower senescence. In contrast, flowers such as daylily are categorized as non-climacteric, because of their insensitivity to ethylene during flower senescence (Panavas, et al., 1998).

Ethylene is a gaseous phytohormone that is known to regulate fruit ripening, plant defense responses, leaf abscission, seed germination and many other processes in plant growth and development (Reid, 1987). The effect of ethylene on plants was observed in the mid 1800's when illuminating gas, used as a source of light, caused damage to a collection of plants (Fahnestock, 1858). It was later discovered, that ethylene was a component of the gas (Wehmer, 1900) and also a component of plant tissues.

Almost a century passed before the ethylene biosynthetic pathway was elucidated:

methionine $\rightarrow$ S-adenosyl methionine (SAM) $\rightarrow$ 1-aminocyclopropane-1-carboxylic acid 
(ACC) $\rightarrow$ ethylene (Adams and Yang, 1979). Two enzymes are involved in the synthesis of ethylene: 1-aminocyclopropane-1-carboxylic acid synthase (ACS), which catalyzes the conversion of S-adenosyl-L-Met (SAM) into ACC, and ACC oxidase (ACO), which catalyzes the conversion of ACC into ethylene (Kende, 1993).

The production of ethylene by senescing climacteric flower petals is autocatalytic, meaning that exposure to ethylene stimulates ethylene biosynthesis (Borochov and Woodson, 1989). Autocatalytic ethylene production has been demonstrated in Petunia corolla senescence, with or without pollination (Hoekstra and Weges, 1986; Singh et al., 1992).

The climacteric rise in ethylene production is mediated through ethylene action. When treated with silver thiosulfate, or other ethylene action inhibitors, flowers do not exhibit the climacteric rise in ethylene production and do not accumulate ACC, the precursor to ethylene production (Veen and Kwakkenbos, 1982). In contrast, exogenously applied ethylene accelerates corolla color changes and wilting of Petunia hybrida (Whitehead et al., 1984).

Since the introduction of the gas chromatograph in the 1950's, researchers have been able to measure ethylene in minute quantities and with more accuracy (Abeles et al., 1992). Many flowers have been studied extensively and have been classified as either ethylene-sensitive or ethylene-insensitive. In ethylene-sensitive flowers, the sensitivity of the petals to ethylene generally increases with age, meaning that more mature petals senesce in response to lower levels of ethylene (Kende and Hanson, 1976; Mayak and Kofranek, 1976). This is not the case for ethylene-insensitive flowers whose demise is not associated with an ethylene climacteric. Numerous species in the Compositae, 
Iridaceae, Liliaceae, and Umbelliferae families are ethylene-insensitive (Woltering and van Doorn, 1988).

Most research has concentrated on the physiology of petal senescence in ethylenesensitive flowers such as carnation, orchids, petunias, morning glory, and roses (Mayak et al., 1972; Kende and Hanson, 1976; Woltering and van Doorn, 1988; Borochov and Woodson, 1989; Hew et al., 1989; Rubinstein, 2000). However, in recent years, research has broadened to include ethylene-insensitive plants, such as daylily, tulips, and iris (Bieleski and Reid, 1992; Lay-Yee et al., 1992; Bieleski, 1995; Jones and McConchie, 1995; Panavas et al., 1999; Rubinstein, 2000; van Doorn et al., 2003). In daylily, the hormone abscisic acid (ABA) is thought to be involved in the regulation of flower senescence (Panavas et al., 1998). In ethylene-sensitive flowers such as carnation, ABA accelerates flower senescence by increasing the endogenous production of ethylene (Ronen and Mayak, 1981).

\section{Cytokinins}

Another group of plant hormones involved in senescence, the cytokinins, were first discovered as a result of efforts to find factors that would stimulate plant cells to divide. Subsequently, cytokinins were shown to affect many other physiological and developmental processes such as chloroplast maturation, control of morphogenesis, mobilization and remobilization of nutrients, and the delay of leaf senescence (Richmond and Lang, 1957; Dervinis et al., 1998) and flower senescence (Chang et al., 2003). Experiments on cytokinin-treated leaf tissue have demonstrated that nutrients, such as amino acids, are preferentially transported to, and accumulate in these tissues (Mothes and Englebrecht, 1961). Cytokinins prevent deterioration of organs, such as leaves, by 
promoting protein synthesis, stimulating RNA synthesis, and causing materials to move to the organs in which cytokinins have come to reside. Cytokinins influence both the redistribution of previously absorbed and synthesized compounds, and the partitioning of new assimilates (Nooden and Leopold, 1988).

Plant roots are the primary sites for cytokinin synthesis, especially the root tip as shown in sunflower and pea plants (Weiss and Vadia, 1965; Short and Torrey, 1972). Cytokinins are abundant in root xylem sap (Kende, 1965) and are transported via the transpiration stream (Van Staden and Davey, 1979). Long-distance transport of cytokinins can also occur in the phloem (Hall and Baker, 1972; Phillips and Cleland, 1972), but their method of transport and role in the phloem remains unclear (Nooden and Leopold, 1988).

There are numerous cytokinins and cytokinin-like compounds. Zeatin is the most common naturally occurring cytokinin in most plants, whereas kinetin and benzylaminopurine (BAP) are synthetic, the latter being an exogenously applied cytokinin for agricultural use.

Several approaches have been used to study the effect of cytokinins in plant senescence, such as exogenous application of cytokinin solutions, measurement of endogenous cytokinins during senescence, and transgene-encoded cytokinin biosynthesis (McCabe et al., 2001). Cytokinin concentration in roses (Mayak et al., 1972), carnation (Van Staden and Dimalla, 1980), and Cosmos sulfureus (Saha et al., 1985) is greatest in young flowers and decreases during corolla opening and development. Exogenously supplied cytokinin suppresses senescence in cut carnation flowers (Van Staden et al., 1988) and delays senescence of Petunia corollas (Taverner et al., 1999). Cytokinins and 
cytokinin-like compounds have been shown to delay the ethylene-climacteric in carnation flowers (Mor et al., 1983; Cook et al., 1985), and decrease the sensitivity of flower petals to ethylene (Mayak and Kofranek, 1976; Mor et al., 1983; Cook et al., 1985). Cytokinin can also delay the climacteric-like rise in respiration (Halevy et al., 1966; Tetley and Thimann, 1974), and the massive increase in solute leakage associated with senescence (Smart, 1994).

\section{Petunia as a model}

Petunia x hybrida has proven to be an ideal model for studying ethylene-sensitive flower senescence because of the abundance of flowers that can be produced year-round in a small area. Petunia also has ideal morphological features, such as its fairly large corolla and its long, single style. The corollas are easily detached and the styles have a distinct stigma, all of which are excellent properties for manipulation (Lovell et al., 1987; Whitehead, et al., 1984). In recent studies, petunia is proving to be a useful model for genetic engineering (Gubrium, et al., 2000; Chang et al., 2003; Dervinis et al., 1998). Comparisons are frequently made between petunia and carnation flowers, because they have a similar life span and their senescence is accompanied by a pronounced ethylene climacteric (Whitehead et al., 1984).

\section{Age-related vs. pollination-induced senescence}

As mentioned earlier, the terms climacteric and non-climacteric describe the relationship of flower senescence to the production of ethylene, or lack thereof. To further distinguish between types of flower senescence two other terms are used: pollination-induced and age-related (unpollinated) senescence. Pollination-induced senescence of a flower is triggered by pollination, whereas age-related senescence 
describes a flower whose development is undisturbed by pollen and therefore has an increased flower longevity. It is important to note that in many flowers pollination serves to accelerate rather than induce developmental changes already occurring in the floral organs during age-related senescence (O’Neill et al., 1993). More specifically, pollination accelerates petal wilting and ethylene biosynthesis observed during the natural senescence of age-related flowers (Stead, 1992). For example, in age-related senescence, petunia flowers display an increase in ethylene production by 6 days after anthesis and a peak by 9 days after anthesis (Whitehead et al., 1984). However, during pollinationinduced senescence petunia flowers display a rapid increase in the production of ethylene within 2 hours of pollination, followed by the first signs of flower senescence within 24 hours (Hoekstra and Weges, 1986).

\section{Pollination-induced senescence}

Pollination triggers a number of physiological responses in the flower, including ethylene synthesis (Hall and Forsyth, 1967) and alteration in metabolite source-sink relations in floral organs (Linskens, 1974). These responses culminate in flower senescence, leading to the onset of fruit development.

Pollination causes considerable acceleration of the visible symptoms of petal senescence, such as discoloration, wilting, and abscission (Halevy, 1986). However, an increase in ethylene biosynthesis from the stigma is the first detectable post-pollination event in many species. Pollination-induced ethylene is produced in different floral organs and is responsible for coordinating post-pollination developmental events such as ovary growth (O’Neill et al., 1993) and petal senescence (Larsen, et al., 1993). 
Two phases of pollination-induced ethylene production have been described in petunia hybrida: an early phase, which reaches a maximum level 4 hours after pollination, and a late phase beginning at about 18 hours after pollination (Whitehead et al., 1984). The early pistillate ethylene ( $<4$ hours) has no function in the acceleration of corolla wilting. It is during this early phase that the wilting stimulus travels from the stigma to the corolla (Gilissen and Hoekstra, 1984).

As mentioned earlier, ethylene is synthesized by two enzymes, ACS and ACO (Kende, 1993). These enzymes are encoded by multigene families in all species researched, thus far (Zarembinski and Theologis, 1994). The effect of pollination on the expression pattern of these genes has been studied in petunia, carnation, geranium, and orchid. Increased ethylene synthesis is accompanied by increased ACS and ACO gene expression and elevated enzyme activities following pollination of these flowers (Woodson et al., 1992; O’Neill et al., 1993; Tang and Woodson, 1996; Jones and Woodson, 1997; Bui and O’Neill, 1998).

\section{Interorgan signaling}

Following pollination, a major developmental switch occurs, inducing changes which involve interorgan signaling within the flower. Pollination-induced signals from the stigma are translocated to other floral organs such as the ovary and corolla. These signals initiate various developmental changes and processes including perianth senescence, pigmentation changes, and ovary maturation. The identity of the transmitted pollination signal has not been elucidated (O’Neill et al., 1993).

Early research on floral organ interactions showed that the stigma and style produced the greatest amounts of ethylene compared to all other flower parts (Hall and 
Forsyth, 1967). Recent work has shown that, following pollination in carnation, ethylene and ACC were highest initially in the stigmatic region of the style, and 24 hours after pollination they were highest in the base. The production of ethylene and ACC increased sequentially in styles, ovaries, and petals (Jones and Woodson 1999). In petunia, severing the entire style from the ovary means removing the main hormone producing organ and causes a delay in the wilting process during senescence. However, removal of the stigma or part of the style induces wilting, indicating that the stigma and style form an undividable complex (Gilissen, 1976). Similar effects of style excision on pollinationinduced corolla abscission were observed in Digitalis (Stead and Moore, 1979).

\section{Macronutrients}

The beneficial effect of adding mineral elements to soils to improve plant growth has demonstrated in agriculture for over 2000 years. Among scientists, however, this was still a matter of controversy until the last century (Taiz and Zeiger, 1991). Now there are two principle criteria by which an element can be judged essential or nonessential to any plant: First, an element is essential if the plant cannot complete its life cycle (form viable seeds) without the presence of that element. Second, an element is essential if it forms part of any molecule or constituent of the plant that is itself essential in the plant (i.e. nitrogen in proteins and magnesium in chlorophyll). It is now generally accepted that certain essential elements, called macronutrients, are necessary for plant growth and without them many plants would exhibit symptoms of nutrient deficiencies. The accepted group of macronutrients is: H, C, O, N, K, Ca, Mg, P, and S (Epstein, 1972).

Nitrogen is used in greater amounts than any of the other macronutrients and generally constitutes the largest percentage of a plant's mineral weight. It is a constituent of amino acids and thus found in all proteins, including enzymes. Nitrogen is generally 
considered to be among the most mobile elements, if not the most mobile and is taken up by the plant in the form of nitrate, and ammonium to lesser degree (Mills and Jones, 1996).

Phosphorus is taken up as phosphate and incorporated into a variety of organic compounds including sugar phosphates, phospolipids, and nucleotides. The main entry point of phosphate into assimilatory pathways occurs during the formation of ATP, the energy currency of the cell. Likewise, a strand of DNA has an absolute requirement for phosphorus in its structure, because phosphate forms the bridging link between each deoxyribonucleoside, and makes up about 25\% of the weight of DNA (Bieleski, 2000).

Potassium, an electrolyte, has an important role in osmoregulation and in water relations in plants. The high mobility of potassium in transport through membranes also enables it to act as counterion for anions both in short- and long-distance transport and in ATPase-stimulated proton efflux (Marschner, 1983). Its roles in activating enzymes involved in protein synthesis and carbohydrate metabolism and in influencing the permeability of cell membranes make it crucial for normal plant growth.

Calcium content in plant tissue affects many processes during growth and development at all stages (Ferguson and Drobak, 1988). Although not a constituent of cell membranes, calcium ions are of fundamental importance for membrane permeability and transport. Calcium is also involved in intra- and intercellular signaling and cell wall stability (Pandey, et al., 2000). Interactions with other cations strongly influence calcium uptake. For instance, cation antagonism by $\mathrm{K}, \mathrm{Mg}$, and $\mathrm{NH}_{4}{ }^{+}$can substantially depress Ca uptake (Kirkby, 1979). The uptake of calcium is considered to be passive, and it is preferentially moved in the xylem (Bangerth, 1979). 
As mentioned above, magnesium has influence on the availability of other cations such as potassium and calcium. Magnesium is an activator of more enzymes than any other element, and is also a constituent of chlorophyll (Epstein, 1972).

Sulfur is actively taken up in the form of sulfate by plant roots. Sulfate is transported to various organs through the xylem stream and used for the synthesis of sulfur-containing amino acids and numerous secondary sulfur metabolites (Leustek and Saito, 1999). Sulfur is essential to protein synthesis as a component of the amino acids methionine, cysteine, and cystine.

\section{Nutrient uptake}

The ability of plants to absorb both water and mineral nutrients from the soil is related to their capacity to develop an extensive root system. Plant roots take up mineral nutrients in ionic form and the concentration of these solutes in plant cells is usually much greater than in the medium in which the roots are growing. There are two reasons for this. Firstly, the organs of plants that are not woody rely on hydrostatic pressure to provide their support, shape, and form. Therefore, a high concentration of osmotically active solutes is needed to provide the driving force for the uptake of water to generate this hydrostatic pressure. Secondly, many proteins require high concentrations of ions for their stability and activation (Flowers and Yeo, 1992).

Initial ion uptake is considered to be passive and may occur by simple diffusion and mass flow. After uptake into the cortical cells, metabolic energy is required in the form of ATP to actively transport nutrients across the plasma membrane. Any solute entering the root must move across, and possibly along, cell walls to gain access to the 
plasma membrane. Once in the xylem, nutrients move by an upward bulk flow driven by evaporative loss of water from aerial organs reducing pressure in the cell walls.

However, phloem transport delivers most of the nutrients required for growth and storage processes. Osmotically generated pressure differences move photosynthetic products and inorganic nutrients (assimilates) by bulk flow from leaves (sources) to heterotrophic organs (sinks) through the phloem. It is the sieve element/companion cell complex that forms the long-distance transport unit. Source loading and sink unloading of sugars, amino and nitrogen containing compounds, and potassium largely account for phloem sap osmotic concentrations and pressure differences. A symplastic component is characteristic of most loading and unloading pathways, but under certain circumstances may be interrupted by an apoplasmic step (Lalonde, et al., 2003). Irrespective of the cellular pathway followed, assimilates are transported across plasma and organellar membranes (Patrick et al., 2001).

\section{Leaf senescence and nutrients}

As in flower senescence, leaf senescence is also a type of programmed cell death (PCD) and is characterized by loss of chlorophyll, lipids, total protein, and RNA (Smart, 1994; Gan and Amasino, 1997). This senescence process is believed to be an evolutionarily acquired, active genetic trait that contributes to plant fitness. For example, senescing leaves remobilize their nutrients to reproductive organs (Oh et al., 1997)

allowing for greater seed production. Nutrient salvage from older or damaged leaves has the adaptive value of recycling nutrients which require the use of costly energy for their acquisition, or which may have limited availability in the surrounding environment (Leopold, 1961). 
A significant amount of information regarding the source/sink relationship in plants has been generated from research on leaf senescence (Smart, 1994). The leaf is a sink for nitrogen and mineral nutrients during the early stages of leaf development. However, once leaf senescence begins the leaf becomes a nutrient source. K, N, P, S and metals are mobilized from the yellowing leaves to new growth or developing seeds (Himelblau and Amasino, 2001). Long-distance transport of these nutrients from senescing leaf tissue to other parts of the plant is thought to take place via the phloem (Hill, 1980). The efficiency with which nutrients are mobilized from senescing leaves is determined by its phloem accessibility and phloem mobility (Bukovac and Wittwer, 1957).

By comparison, the source/sink behavior during leaf senescence is not identical to that of petal senescence. The leaf does switch from being an importer to an exporter, but this occurs early in its life while growth is still taking place (Bieleski and Redgwell, 1985; Turgeon, 1989), and this switching process generally takes several days, not a few hours. After the switch occurs, the leaf primarily spends all of its life as an exporter, shipping out carbohydrate produced by photosynthesis. During export, the transport process is slow and does not undergo major change while moving materials out of the leaf. In contrast, flowers such as Asiatic lily and daylily petals undergo a rapid change during the transport process, exhibiting a very rapid switch, in less than $12 \mathrm{~h}$, from powerful sink to powerful source (Bieleski, 2000).

\section{Studies on floral nutrient remobilization}

Few studies have addressed changes in mineral nutrient concentrations among individual floral organs, instead focusing on nutrient concentrations of the whole flower 
as shown in roses, Juglans regia L., and Lupinus havardii (Drossopoulos et al., 1996; Tamimi et al., 1999; Picchioni, et al., 2001). However, recently it was demonstrated that remobilization of nitrogen, phosphorus, and potassium from corollas occurred before and during flower senescence in Petunia x hybrida, while fresh weight and ethylene production followed patterns expected of climacteric flowers (Verlinden, 2003). Following pollination of Arachnis orchid flowers, the mobilization and transport of soluble amino nitrogen and phosphorus was observed from the perianth to the column and ovary (Hew, et al., 1989). Likewise, in Cymbidium and Cattleya flowers, sugar, protein, and phosphate remobilization from perianth to ovary following pollination has also been reported (Gessner, 1948; Hsiang, 1951; Harrison and Arditti, 1976; Oertli and Kohl, 1960).

Some related studies have evaluated the source/sink relationship between different floral organs, specifically the petals and ovary. For instance, as the ovary of the Brodiaea flower ages, it becomes a very strong sink for carbohydrate from either the stem or senescing petals (Han et al., 1991). In the aforementioned study of Arachnis, it was observed that the gains in nitrogenous compounds and phosphorus in the column and ovary were much greater than the actual loss from the perianth, indicating that the source of the gains was from adjacent leaves or other flowers (Hew, et al., 1989). Similar results were shown in carnations where petal senescence is also accompanied by growth of the ovary (Nichols, 1973). Mor et al. (1980) found that removal of petals the day of carnation flower harvest did not reduce the accumulation of dry matter in the ovary, indicating the redistribution of metabolites from the senescing petals does not contribute substantially to ovary growth (Borochov and Woodson, 1989). In Lilium, a hierarchic 
nutritional correlation exists between the floral organs, with the anther representing the highest sink strength during pollen development, subsequently followed by increased sink strength in the surrounding floral organs after anther maturation (Clement et al., 1996).

For this research, one hypothesis was that significant amounts of nutrients are moved between flower organs and/or the whole plant during development and senescence. Also, it was hypothesized that transgenic petunias would have different macronutrient remobilization patterns compared to their wild-type counterparts, and that pollination-induced and age-related senescence of petunias would have similar patterns of nutrient remobilization.

With the hypotheses in mind, the objectives were two-fold. The first objective was to measure fresh weight, dry weight, and macronutrient (C, N, P, K, Ca, Mg, and S) contents from bud stage through senescence in the corollas, ovaries, and styles of four varieties of Petunia x hybrida. The second objective was to investigate the hormonal influence on changes in macronutrient contents from bud stage through senescence by comparing two transgenic lines of Petunia x hybrida to their wild-type counterparts.

The results of this research will help to further elucidate the role of mineral nutrients during flower development and senescence. Because the different minerals have specific known roles, the changes in mineral nutrient concentrations during senescence may indicate which enzymes or processes are decreasing and when, and point the way to further studies. 


\section{CHAPTER TWO: Age-Related Senescence}

\section{Introduction}

Flower aging is accompanied by typical changes in petal color, shape, fresh weight, and metabolic processes. Age-related alterations in the water content of the flower are widely thought to be a result of changes in the ability of the membranes to retain solutes within the cell (Halevy and Mayak, 1979; Borochov and Woodson, 1989). Flower senescence in many plants, including Petunia x hybrida, is also associated with a significant increase in production of ethylene, which plays a regulatory role in the demise of petals or corollas in several plant species (Borochov and Woodson, 1989; Reid and Wu, 1991).

It is important to note that even though flowers are distinguished as being either ethylene-sensitive or ethylene-insensitive, all higher plants produce ethylene. Two systems of ethylene production are believed to operate, and can assist in distinguishing between ethylene sensitivity and insensitivity. System-1 represents the basal levels of ethylene production detected in all plant tissue including flowers, while system-2 represents the shift to autocatalytic ethylene production observed during petal senescence and fruit ripening (Yang and Hoffman, 1984; Kende, 1993; Woodson, 1994). The switch from system-1 to system-2 requires the tissue to develop an increased sensitivity to ethylene (Whitehead, 1994). To further understand the regulatory role of ethylene in flower senescence, genetic engineering has produced CaMV35Setr1-1, an ethylene insensitive petunia transformed using the background of wild-type Mitchell Diploid (Gubrium et al., 2000). 
Cytokinins have long been known to delay senescence in detached leaves (Richmond and Lang, 1957) and more recently in flowers (Van Staden et al., 1988; Chang et al., 2003). A transgenic petunia, SAG12-IPT was engineered to overproduce cytokinin, which in turn decreased the sensitivity to ethylene within the flower (Chang et al., 2003). Cytokinin applied to carnation flowers delayed senescence and was associated with reduced ethylene biosynthesis and decreased sensitivity to ethylene (Eisinger, 1977; Mor et al., 1983; Cook et al., 1985). Relatively few additional studies on the interactions of hormones during flower senescence exist. Even less research on the interaction of hormones and nutrient remobilization during flower senescence is available.

\section{Materials and Methods}

Plant material. Four varieties of Petunia x hybrida were used in this study: Mitchell Diploid and V26 (may be referred to as wild-type from this point on), and their respective transgenic counterparts, CaMV35Setr1-1 (line 44568) and SAG12IPT (line 197-1-7) (All seeds were obtained from Dr. David G. Clark, University of Florida, Gainesville, Florida). Seeds were sown separately in quarter flats using a peatlite plug mix (Sunshine Mix \#5, Seba Beach, AB, Canada) and placed in a mist-bed with $28^{\circ} \mathrm{C}$ bottom heat to improve germination. When seedlings reached approximately 1.5 cm in height, 45 plants per variety were transplanted into flats with cell-packs using a peat-lite media (Sunshine Mix \#1, Seba Beach, AB, Canada). These flats were moved into a glasshouse with day and night temperatures set at 21 and $18^{\circ} \mathrm{C}$, respectively. Once the plants reached approximately $6 \mathrm{~cm}$ in height, they were transplanted into $25.4 \mathrm{~cm}$ pots, three plants per pot (15 pots per variety). When adequate stem and root mass was

produced, a final transplant was made to $11.37 \mathrm{~L}$ pots using the same media. Plants were 
grown under natural light conditions from January to May and were fertilized at every watering with $250 \mathrm{mg} \cdot \mathrm{L}^{-1}$ nitrogen based on a $20 \mathrm{~N}-4.4 \mathrm{P}-16.6 \mathrm{~K}$ fertilizer (Peters Professional 20-10-20, Fogelsville, PA).

Experimental design and tissue collection. Plants were grown at the West Virginia University greenhouse in Morgantown, WV, latitude $39^{\circ} 39^{\prime} \mathrm{N}$ and longitude $79^{\circ}$ 55' W. The greenhouse was an even-span structure composed of glass and a truss frame, with the ridge of the apex running east to west.

The four petunia varieties (two wild-type and two transgenic lines) were grown within a randomized complete block. To collect plant tissue for age-related senescence, 20 flowers, chosen at random for each of the four varieties, were tagged and emasculated immediately preceding anthesis to avoid accidental pollination. Everyday thereafter, 20 additional flowers, also chosen at random, were tagged and emasculated until the flowers tagged on the first day were completely senesced. The final day of senescence varied for each petunia variety. All of the tagged flowers were harvested at this time and the corollas, ovaries, and styles were separated from each other into sets. Fresh weights for each set of organs were taken immediately before placing them in paper bags. The organs were subsequently dried overnight in a $75^{\circ} \mathrm{C}$ oven (Fisher Isotherm Incubator, Pittsburgh, PA). Upon removal from the oven the following day, a dry weight measurement was taken for each set of organs before grinding them to a powder in a mortar with a pestle to pass a 40-mesh screen. The ground tissue was then wrapped in wax paper, placed back into the paper bags, and stored at $-80^{\circ} \mathrm{C}$ for later analysis. These steps were repeated until three subsamples for each variety were completed. 
Carbon, nitrogen, and sulfur analyses. Total carbon, nitrogen, and sulfur content for corollas, ovaries, and styles were measured using a LECO 2000 CNS carbonnitrogen-sulfur analyzer (LECO Inc., MI). For each variety and subsample, $100 \mathrm{mg}$ of previously dried, ground, and stored tissue for each flower part was weighed and placed in furnace boats for analysis. These steps were repeated until three carbon, nitrogen, and sulfur subsamples of each tissue and variety were completed.

Phosphorus, potassium, calcium, and magnesium analyses. One hundred mg of dried and ground tissue was weighed and placed in $50 \mathrm{ml}$ beakers. The tissue was subsequently digested in $5 \mathrm{ml}$ of concentrated $\mathrm{HNO}_{3}$ and $3 \mathrm{~mL}$ of $30 \% \mathrm{H}_{2} \mathrm{O}_{2}$. The reaction was allowed to come to completion overnight. Next, the samples were filtered through Whatman no. 42 ashless filter paper, brought to $50 \mathrm{ml}$ total volume with $\mathrm{dd}_{2} \mathrm{O}$, and stored at $-80^{\circ} \mathrm{C}$ until further analysis. These steps were repeated until three subsamples per variety were complete. Phosphorus, calcium, and magnesium contents were measured on an inductively coupled plasma-optical emission spectrometer, or ICP (PerkinElmer P400, Norwalk, CT). Potassium content was measured on a PerkinElmer AAnalyst 100 atomic absorption spectrometer equipped with an autosampler (PerkinElmer, Norwalk, CT).

Statistical analyses. Linear regressions were performed on corolla fresh weight, dry weight, and carbon content in order to evaluate absolute contents and rates of changes in these measurements (SAS software, SAS Institute, Cary, NC). 


\section{Results}

\subsection{Corollas (Mitchell Diploid and CaMV35Setr1-1)}

3.11. Fresh and dry weight. The fresh and dry weight of Mitchell corollas increased sharply prior to anthesis (Fig. 2.1A and B), and then remained relatively constant through day 6 , with a temporary decrease at day 5 . The amount of dry weight declined by over one third following anthesis through senescence for both Mitchell and CaMV35Setr1-1. After day 6, Mitchell corolla fresh weight decreased at a faster rate than dry weight as the flower senesced, by $0.0553 \mathrm{~g} . \mathrm{d}^{-1}$ and $0.0026 \mathrm{~g} . \mathrm{d}^{-1}$, respectively (Table 2.1). CaMV35Setr1-1 fresh weight remained constant from anthesis through day 12, and subsequently declined slowly until the complete collapse of the tissue (Fig. 2.1A). Dry weight of the corollas was similar to Mitchell corolla dry weight from anthesis through day 4. However, CaMV35Setr1-1 diverged from Mitchell patterns of changes in dry weight by decreasing until day 9 where it remained at the same level through completed senescence (Fig. 2.1B).

3.12. Carbon. The amount of carbon in Mitchell corollas decreased by almost $50 \%$ from anthesis through senescence, and followed a similar pattern to the observed losses in dry weight (Fig. 2.1C). CaMV35Setr1-1 carbon content decreased from anthesis through day 9 and then remained constant through senescence, a pattern that similarly reflects changes in the dry weight.

3.13. Macronutrients. Nitrogen and sulfur content of Mitchell corollas showed similar changes throughout corolla development and senescence (Fig. 2.2A and 2.3C). Both elements increased in concentration until anthesis, and then remained constant through day 6, except for a temporary decrease at day 5 , which is similar to changes 
observed in corolla fresh and dry weight. After day 6 there was a steady decrease in nitrogen and sulfur through senescence. Phosphorus, magnesium, and potassium contents increased until two days after anthesis, subsequently showing a steady decline through day 5 (Fig. 2.2B and C; 2.3B). This was again followed by an abrupt increase at day 6 similar to observations in fresh and dry weight, nitrogen, and sulfur content changes. After this point phosphorus and magnesium decreased more dramatically than the content of potassium, which remained fairly constant through senescence. Calcium increased nearly four-fold from anthesis through day 9, showing only a slight decrease at day 5 (Fig. 2.3A).

In CaMV35S-etr1-1, changes in nitrogen and sulfur content of corollas showed similar patterns from anthesis through senescence, mimicking changes observed in Mitchell corollas (Fig. 2.2A and 2.3C). The slight decreases in content observed in Mitchell corollas at day 5 were not observed. However, a slight increase was observed from day 9 through day 11, reminiscent of the pattern at day 5 and 6 in Mitchell corollas. Magnesium and calcium contents increased from anthesis through senescence two and six-fold, respectively (Fig. 2.3A and B). Phosphorus and potassium showed peaks in content at day 4 and day 12, respectively, with a slight overall increase in content from anthesis through senescence (Fig. 2.2B and C).

\subsection{Corollas (V26 and SAG12-IPT)}

3.21. Fresh and dry weight. V26 fresh and dry weights increased rapidly prior to anthesis at rates of 0.0719 g. $\mathrm{d}^{-1}$ and $0.0093 \mathrm{~g} . \mathrm{d}^{-1}$, respectively, then remained relatively constant until day 6 (Fig. 2.4A and B; Table 2.1). Fresh weight showed a faster decline than dry weight from day 6 through senescence. Corolla fresh and dry weight of SAG12- 
IPT increased rapidly until one day after anthesis (Fig. 2.4A and B). Fresh weight remained constant through day 9, except for a slight decrease at day 8. Dry weight decreased steadily from day 1 through senescence.

3.22. Carbon. The carbon content of both V26 and SAG12-IPT showed similar changes throughout corolla development to those found in their respective dry weights (Fig. 2.4C). Each increased until one day after anthesis, followed by a steady decrease through senescence.

3.23. Macronutrients. Calcium and magnesium content of V26 increased six-fold and two-fold, respectively, from anthesis through senescence (Fig. 2.6A and B). Nitrogen and sulfur content increased until day 1 , followed by a slight decline through day 6 and a steep decline through senescence (Fig. 2.5A and 2.6C). Potassium decreased slightly after anthesis and then increased abruptly after day 8 (Fig. 2.5C). Calcium content of SAG12-IPT increased four-fold from anthesis through senescence, whereas magnesium remained relatively constant (Fig. 2.6A and B). Nitrogen and sulfur contents showed similar changes throughout development with a gradual decrease in overall content of these respective elements from anthesis through senescence (Fig. 2.5A and 2.6C). Phosphorus content remained constant from anthesis through day 9, followed by a decrease through senescence.

\subsection{Ovaries (Mitchell Diploid and CaMV35Setr1-1)}

3.31. Fresh and dry weight. Mitchell fresh and dry ovary weight increased gradually over time (Fig. 2.7A and B). The ovary dry weight of CaMV35Setr1-1 remained fairly constant from anthesis through day 11 , interrupted by an abrupt decrease at day 12, followed by a steady increase through senescence (Fig. 2.7B). 
3.32. Carbon. The changes in carbon content of Mitchell ovaries had a similar pattern to the changes in dry weight of the ovaries (Fig. 2.7C). The carbon content of CaMV35Setr1-1 ovaries remained relatively constant over time (Fig. 2.7C).

3.33. Macronutrients. Nitrogen, phosphorus, calcium, magnesium, and sulfur contents increased over time in Mitchell ovaries (Fig. 2.8A and B; 2.9A and C). Potassium content increased until day 6, except for an abrupt decrease at day 5 (Fig. 2.8C) followed by a gradual decrease through senescence. Phosphorus, calcium, and magnesium contents of CaMV35Setr1-1 ovaries increased over time, except for the abrupt decrease that can be noted on day 12 (Fig. 2.8B; 2.9A and B). Sulfur content increased until day 7, then declined through day 11 and leveled-off through senescence (Fig. 2.9C). Potassium content had an overall decrease after anthesis through day 12, followed by a final and slight increase at day 13 (Fig. 2.8C).

\subsection{Ovaries (V26 and SAG12-IPT)}

3.41. Fresh and dry weight. The fresh weight of V26 ovaries increased throughout flower development and senescence (Fig. 2.10A). The dry weight increased until day 3, and then remained relatively constant through senescence (Fig. 2.10B). SAG12-IPT ovary fresh weight increased from 3 days prior to anthesis through senescence, with a rapid increase observed at day 9 (Fig. 2.10A). Dry weight increased until day 9, followed by a decrease through senescence (Fig. 2.10B).

3.42. Carbon. V26 ovary carbon content followed a similar pattern to changes in dry weight, increasing until day 3, and subsequently leveling-off (Fig. 2.10C). Carbon content of SAG12-IPT ovaries also followed a similar pattern to dry weight (Fig. 2.10C). 
3.43. Macronutrients. Nitrogen and sulfur contents in V26 and SAG12-IPT ovaries followed similar patterns to their respective dry weights, except for SAG12-IPT ovary sulfur content, which continued to increase after day 9 (Fig. 2.11A and 2.12C). Phosphorus, calcium, and magnesium increased over time in both V26 and SAG12-IPT ovaries (Fig. 2.11B; 2.12A and B).

\subsection{Styles (Mitchell and CaMV35Setr1-1)}

3.51. Fresh and dry weight. Mitchell style fresh and dry weight increased until anthesis, after which the weights remained relatively constant except for the temporary decrease at day 5 also observed in corollas (Fig. 2.13A and B). After day 6, fresh and dry weight decreased through senescence. The dry weight of CaMV35Setr1-1 styles remained the same from anthesis to day 8 and increased slightly from day 8 through senescence (Fig. 2.13B).

3.52. Carbon. The changes observed in carbon content of both Mitchell and CaMV35Setr1-1 styles followed the changes in their respective dry weights and were therefore similar to the patterns observed for corollas and ovaries (Fig. 2.13C).

3.53. Macronutrients. The nitrogen content of Mitchell and CaMV35Setr1-1 styles remained relatively constant after anthesis, mimicking patterns of their respective dry weights and carbon contents (Fig. 2.14A). Phosphorus and potassium contents increased gradually over time in both Mitchell and CaMV35Setr1-1 (Fig. 2.14B and C).

\subsection{Styles (V26 and SAG12-IPT)}

3.61. Fresh and dry weight. V26 and SAG12-IPT style fresh and dry weight increased until anthesis, then remained constant through senescence, except for V26 which showed a noticeable decrease after day 7 (Fig. 2.16A and B). 
3.62. Carbon. The carbon content in the styles of V26 and SAG12-IPT showed a similar pattern to their respective dry weights (Fig. 2.16C).

3.63. Macronutrients. Nitrogen and phosphorus contents of V26 styles remained relatively constant following anthesis (Fig. 2.17 and B). Potassium, calcium, and magnesium contents increased gradually over time in both V26 and SAG12-IPT, with calcium increasing by $90 \%$ and 70\%, respectively, following anthesis (Fig. 2.17C; $2.18 \mathrm{~A}$ and B).

\section{Discussion}

The results of this study indicate that development and senescence of the flowers of the four petunia varieties used in our experiments can be characterized by three distinct developmental phases: a growth phase, maintenance phase, and senescence phase. Clear statistical breaks can be observed between these phases supporting the contention that flower development can and should be discussed in terms of these three distinct developmental phases (Fig. 2.1, 2.4, and 3.1; Table 2.1 and 3.1). Therefore, any further discussion of fresh weight, dry weight, and macronutrient changes of corollas, ovaries, and styles will be related to these three phases of flower development. The developmental phases of corollas will also serve as the model for discussions in styles and ovaries, because corollas are the best overall indicators of floral senescence due to their size, visible cues, and distinct ethylene climacteric. Most research has discussed flower senescence in terms of arbitrary temporal divisions or differing stages of petal development, as in carnation (Nichols, 1966). As far as can be ascertained, only one study, dealing with age-related changes in roses, characterized flower development by a growth and senescence phase, but not a maintenance phase (Itzhaki, et al., 1990). The 
necessity for the description of a maintenance phase during age-related senescence is supported by a floral longevity model which states that floral senescence should occur when the expected fitness gain per unit of floral maintenance investment diminishes to the point where it becomes more profitable to construct a new flower than to maintain an existing one (Ashman and Schoen, 1994). In other words, there is a fixed pool of resources for flowering, thereby creating a trade off between the number of flowers constructed and the maintenance of each flower.

The significant losses of corolla fresh and dry weight, that were observed in this research throughout flower senescence, have previously and extensively been documented in petunia, orchid, and carnation (Hew, et al., 1989; Verlinden, 2003; Borochov and Woodson, 1989) and are considered to be universal changes associated with flower senescence (Rubinstein, 2000). The initial increase in fresh weight during the growth phase is the result of a large volume of solutes and water moving into the cells. In contrast, the loss in fresh weight results from changes in the ability of the membranes to retain these solutes causing decreased water uptake, and is marked by a significant loss of water during the ethylene climacteric in petals (Borochov and Woodson, 1989). Interestingly, in CaMV35Setr1-1, an ethylene-insensitive petunia, the corollas are "empty shells” when compared to the fresh weight of Mitchell, and exhibit less water uptake (Fig. 2.1A).

The decrease in dry weight of corollas is thought to result from tissue respiration and remobilization of cellular constituents (Borochov and Woodson, 1989). The similarity in the patterns of dry weight and carbon is mostly likely because carbon content makes up the bulk of the corolla. Carbon losses in Mitchell, CaMV35Setr1-1, 
and SAG12-IPT corollas occur at slightly lower rates than dry weight losses (Table 2.1), and have previously been demonstrated in Mitchell (Verlinden, 2003). However, in V26, the rate of decline in corolla carbon content exceeds that of dry weight during the senescence phase. In CaMV35Setr1-1, the declines in corolla carbon content and dry weight show similar patterns to those of its wild-type counterpart, and can therefore probably be considered independent of ethylene (Fig. 2.1B and C).

Nitrogen and phosphorus are highly mobile elements (Marschner, 1995).

Studies have shown movement of these elements from flower tissue of orchid (Hew et al., 1989) and from leaf tissue of soybean and Arabidopsis (Mauk and Nooden, 1992;

Himelblau and Amasino, 2001). In this study, nitrogen and phosphorus is remobilized from age-related corollas in V26, SAG12-IPT, and Mitchell during the senescence phase, and again in Mitchell during the pollination-induced senescence phase (Fig. 2.2A and B; 2.5A and $\mathrm{B} ; 3.2 \mathrm{~A}$ and $\mathrm{B})$. Ethylene is thought to facilitate movement of inorganic and organic materials by increasing the permeability of cell membranes (Hanson and Kende, 1975). In CaMV35Setr1-1, the declines in phosphorus and nitrogen contents during the senescence phase are much less dramatic, indicating that the perception of ethylene may be necessary for the remobilization of these minerals (Fig. 2.2A and B).

Magnesium is considered to have low mobility in the phloem (Marschner, 1983), and is not remobilized from leaves of peas (Marschner, 1995) and Arabidopsis (Himelblau and Amasino, 2001). In contrast, magnesium remobilization from the leaves of soybean and wheat has been shown (Mauk and Nooden, 1992; Hocking, 1994). In corollas of Mitchell, magnesium is remobilized during the senescence phase, but this is 
not the case for V26, SAG12-IPT, and CaMV35Setr1-1 (Fig. 2.3B and 2.6B). Therefore, magnesium mobility in the phloem appears to be species, or even cultivar dependent.

Calcium is considered to be immobile in the phloem (Bukovac and Wittwer, 1957) as shown in the senescing leaves of wheat and pea (Hocking, 1994; Marschner, 1995). However, despite its apparent immobility, calcium appears to be remobilized from soybean leaves (Mauk and Nooden, 1992). This remobilization of calcium also occurs from the senescing corollas of Mitchell during pollination-induced senescence (Fig. 3.3A), indicating that calcium mobility may also be species or cultivar dependent.

In SAG12-IPT, the changes in corolla fresh weight, dry weight, and macronutrient content are similar to the wild-type V26, except for a more prolonged maintenance phase, most likely due to increased cytokinin production and therefore a sustained ability to act as a sink, as observed in leaves (Smart, 1994). In contrast, the fresh weight and macronutrient content of CaMV35Setr1-1 show very different patterns during the corolla maintenance and senescence phases compared to wild-type Mitchell, again, indicating that ethylene is most likely involved in the remobilization of nutrient content in floral organs.

Interestingly, Mitchell corollas exhibit a consistent decrease in fresh weight, dry weight, $\mathrm{N}, \mathrm{P}, \mathrm{K}, \mathrm{Mg}$, and S between day 4 and day 6, immediately preceding the senescence phase (Fig. 2.1 and 2.3). A similar temporary decrease can be seen in the styles of Mitchell, also occurring between day 4 and 6 in fresh weight, dry weight, carbon, and nitrogen, although the decline is less pronounced compared to corollas (Fig. 2.13A-C and 2.14A). The meaning of this temporary decrease is unclear and has not been suggested in previous studies. However, upon closer examination this decrease can 
be seen in one previous study (Verlinden, 2003). Senescence is "organized disorganization” (Solomos, 1988) and perhaps, to remobilize materials out of senescing tissue, there has to be a movement of materials into the tissue, requiring an abundance of biological energy for its occurrence. Although senescence is a degradative process, increases in protein synthesis (Woodson and Handa, 1987) and enzyme synthesis (Winkenbach and Matile, 1970) are necessary for petal senescence. It has also been suggested that the climacteric respiratory burst is necessary to produce ATP adequate for sustaining these processes (Solomos, 1988).

During normal flower development there is an increase in ovary growth and dry matter as shown in carnation (Nichols, 1973; Mor et al., 1980), brodiaea (Han et al., 1991), and petunia (Fig. 2.7A and B). In Mitchell, the ovary dry weight, by comparison, represents only $4-5 \%$ of the corolla dry weight, indicating that the ovary is only a small portion of the total flower. The gains in elemental compounds shown in the ovary of all Petunia varieties were much less than the losses from the corolla, indicating that most of the nutrients remobilized from the corollas are moving elsewhere, back into the green plant. Changes in ovary macronutrient content of CaMV35Setr1-1 are erratic, suggesting that ethylene has an effect on nutrient remobilization in this floral organ (Fig. 2.7 and 2.9).

In Mitchell styles, dry weight is 5-10\% of the dry weight of corollas, by comparison, and thereby contributes little to the overall flower weight. The patterns of fresh weight, dry weight, and carbon of Mitchell styles are similar to the corollas, with a temporary decline at day 5 during the maintenance phase, although this decline is less pronounced in styles (Fig. 2.13A and C). 
In conclusion, results indicate that fresh and dry weight of Mitchell, V26, and SAG12-IPT corollas followed patterns previously observed in climacteric flowers. A temporary increase in fresh weight, dry weight, and macronutrients of Mitchell corollas not previously described - occurred at the expected onset of the ethylene climacteric of the flowers. Cytokinin overproduction in SAG12-IPT prolonged the maintenance phase during age-related senescence. Significant increases in fresh weight, dry weight, and selected macronutrient concentrations of ovaries were observed in all examined Petunia varieties. Also, remobilization of selected macronutrients occurred during the corolla senescence phase of all petunia varieties in this experiment, but seemed to contribute only small amounts to the growth of ovaries. 

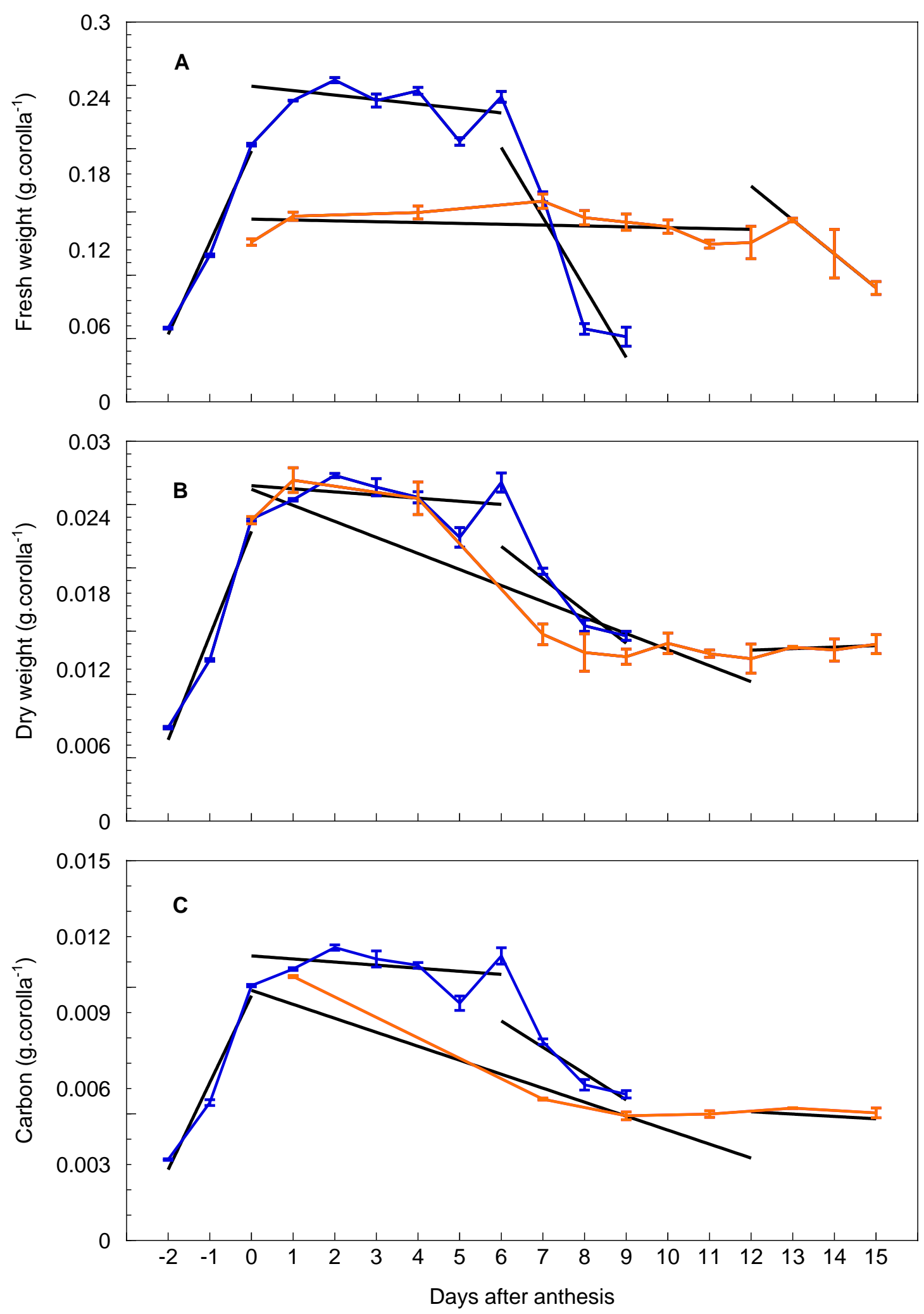

Fig. 2.1. Changes in Fresh weight (A), Dry weight (B), and Carbon content (C) of corollas during flower development and senescence of Mitchell (-) and CaMV35Setr1-1 (-). 

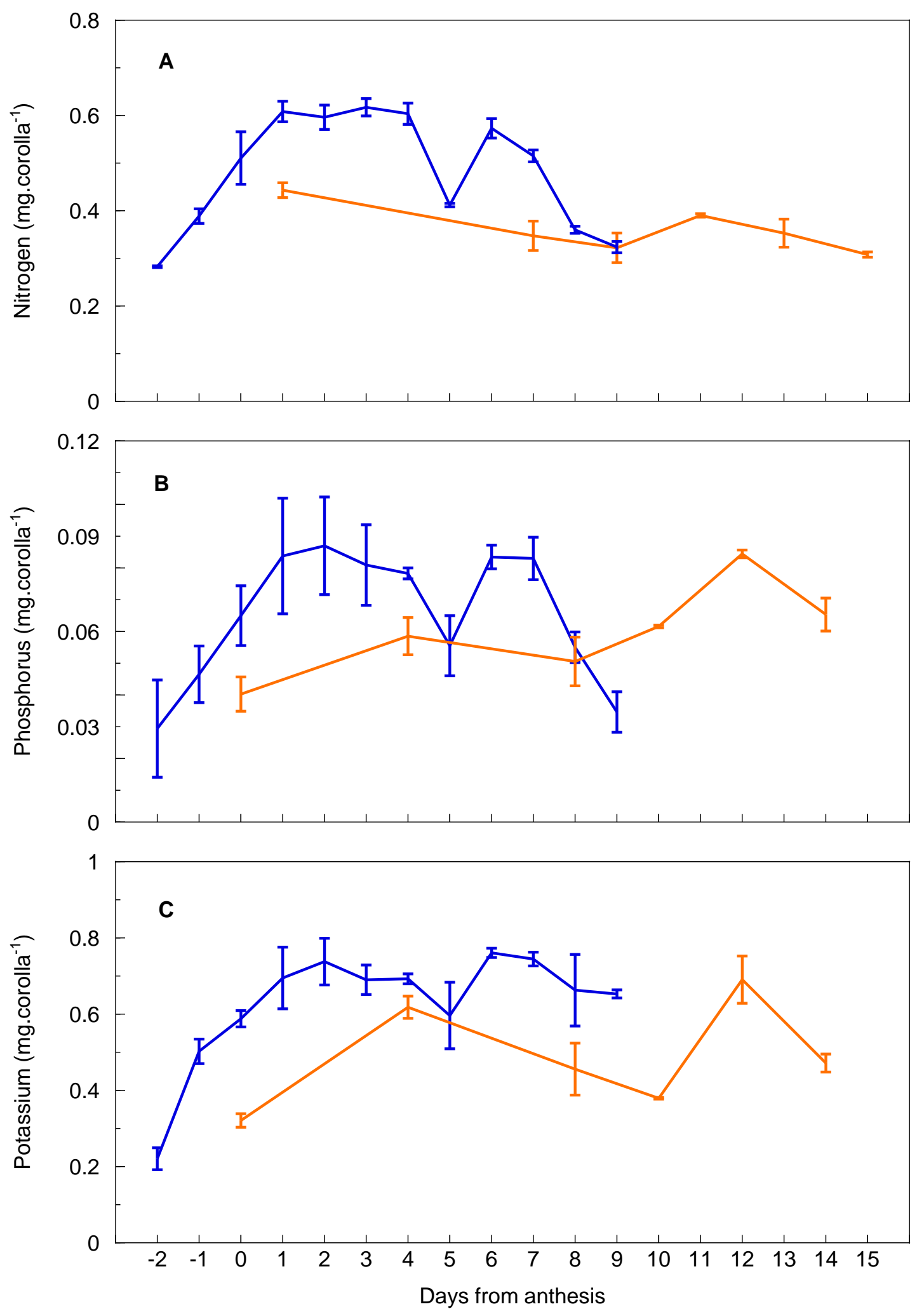

Fig. 2.2. Changes in Nitrogen (A), Phosphorus (B), and Potassium (C) content of corollas during flower development and senescence of Mitchell $(-)$ and CaMV35Setr1-1 (-). 

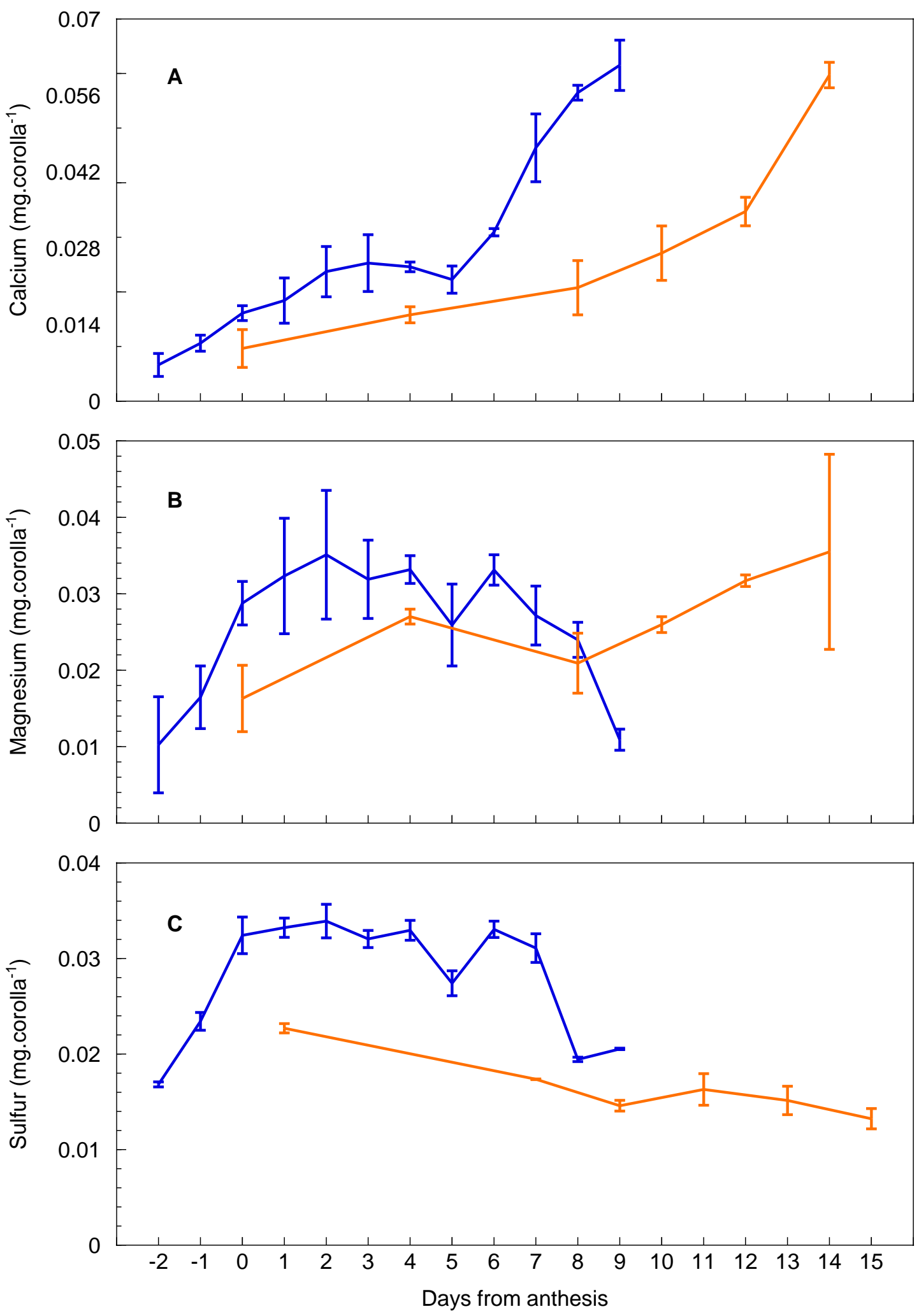

Fig. 2.3. Changes in Calcium (A), Magnesium (B), and Sulfur (C) content of corollas during flower development and senescence of Mitchell $(-)$ and CaMV35Setr1-1 (-). 

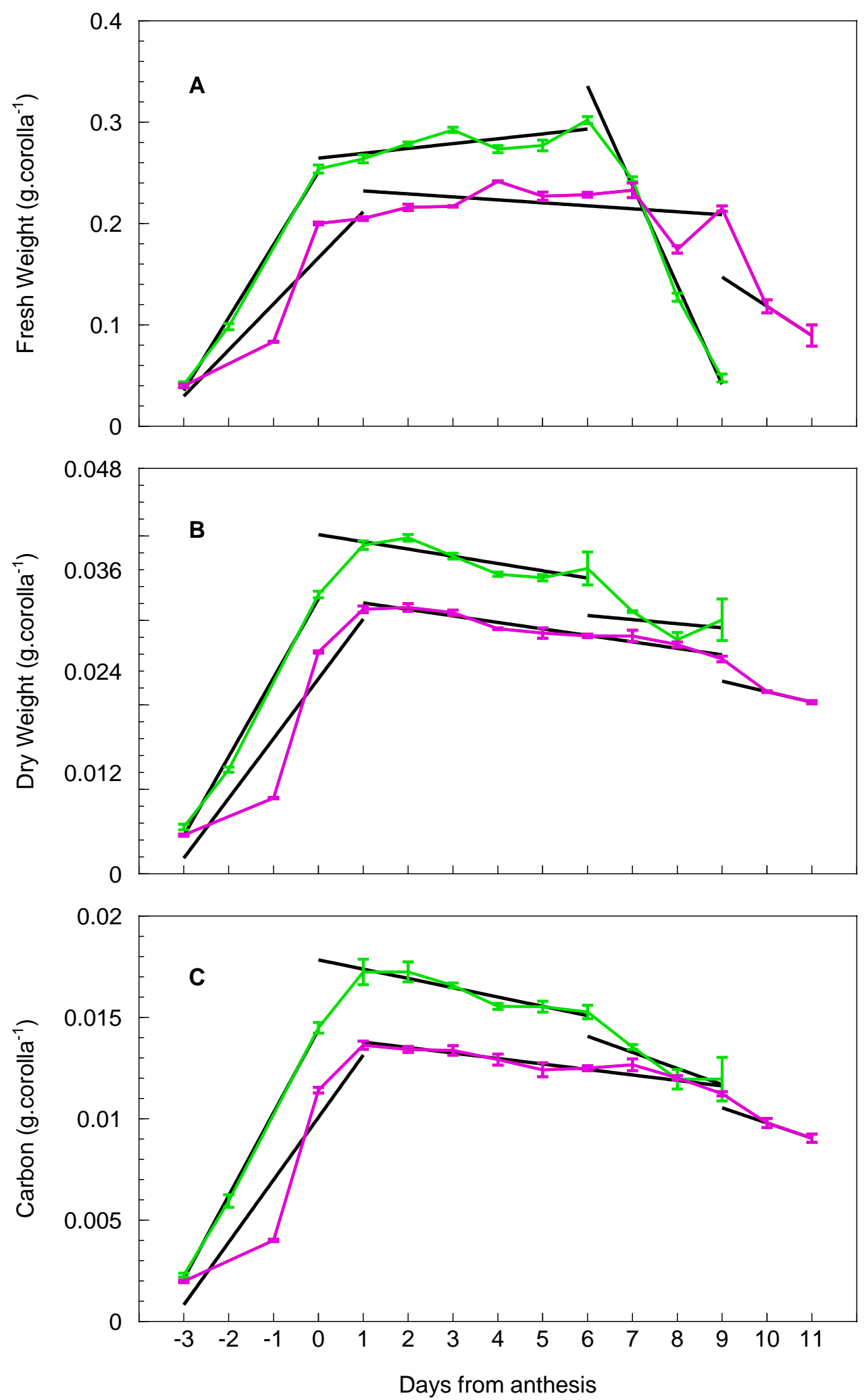

Fig. 2.4. Changes in fresh weight (A), Dry weight (B), and Carbon content $(C)$ of corollas during flower development and senescence of V26 (-) and SAG12-IPT (-). 

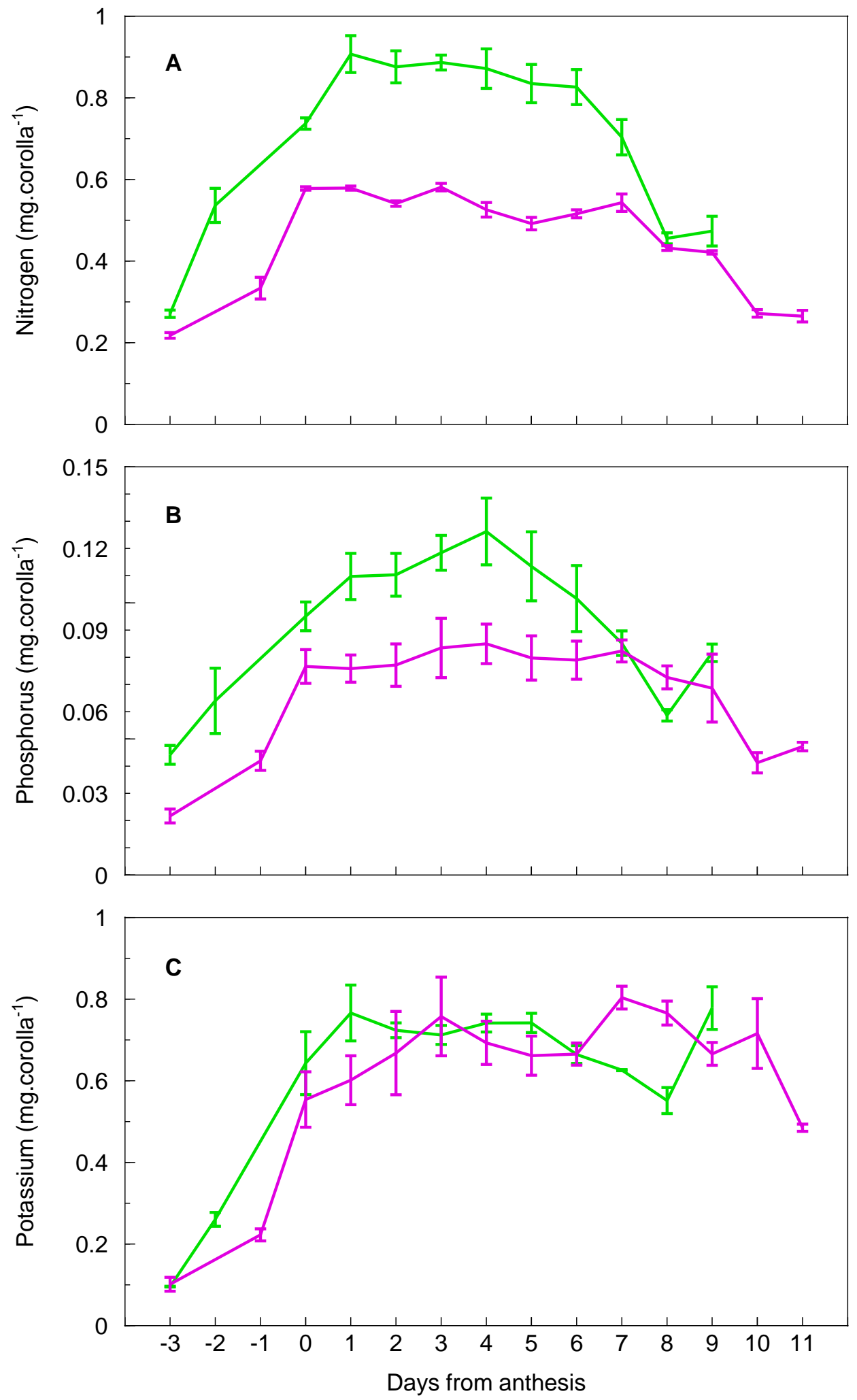

Fig. 2.5. Changes in Nitrogen (A), Phosphorus (B), and Potassium (C) content of corollas during flower development and senescence of V26 (-) and SAG12-IPT (-). 

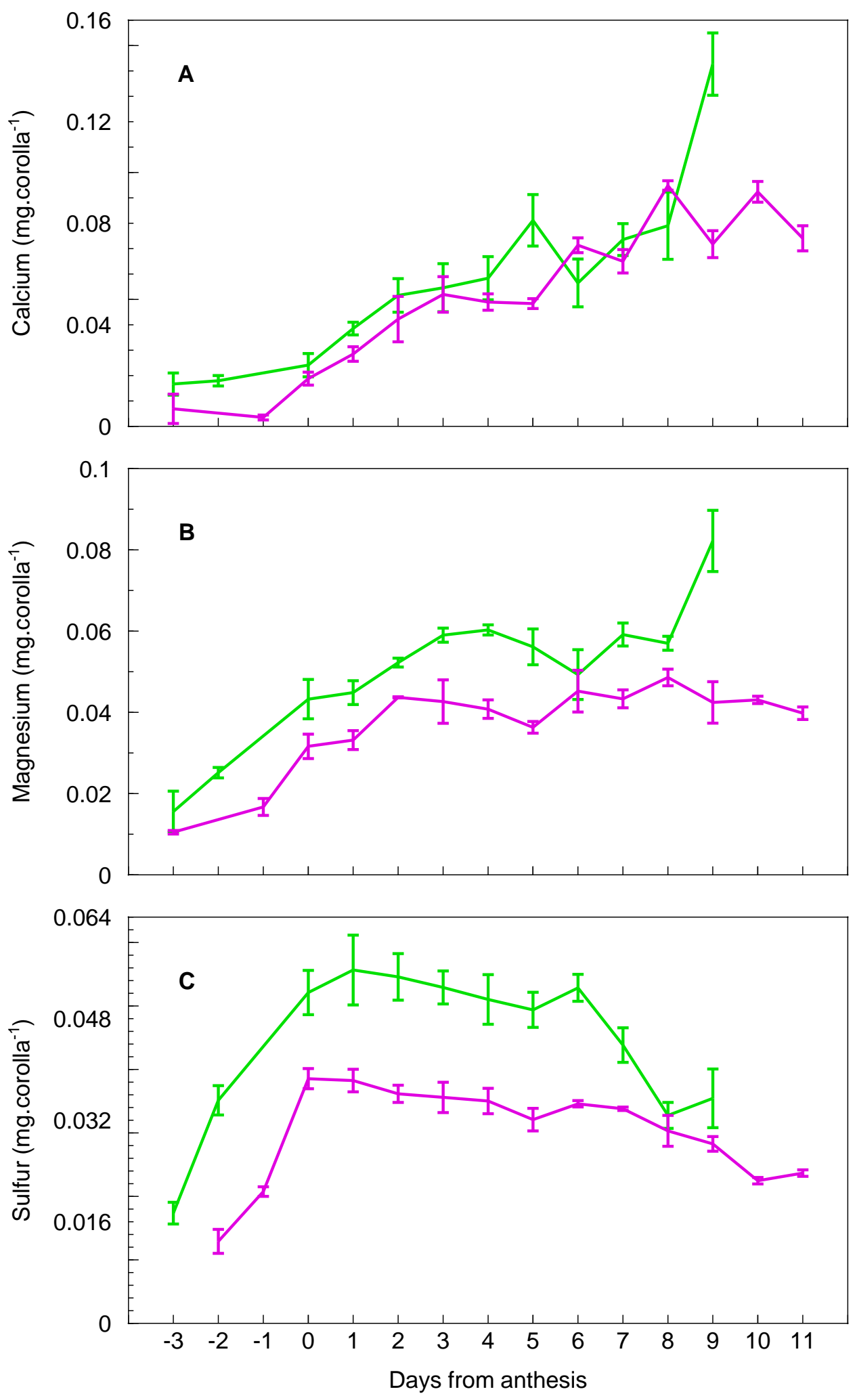

Fig. 2.6. Changes in Calcium (A), Magnesium (B), and Sulfur (C) content of corollas during flower development and senescence of V26 (-) and SAG12-IPT (-). 



Fig. 2.7. Changes in Fresh weight (A), Dry weight (B), and Carbon content (C) of ovaries during flower development and senescence of Mitchell (-) and CaMV35Setr1-1 (-). 

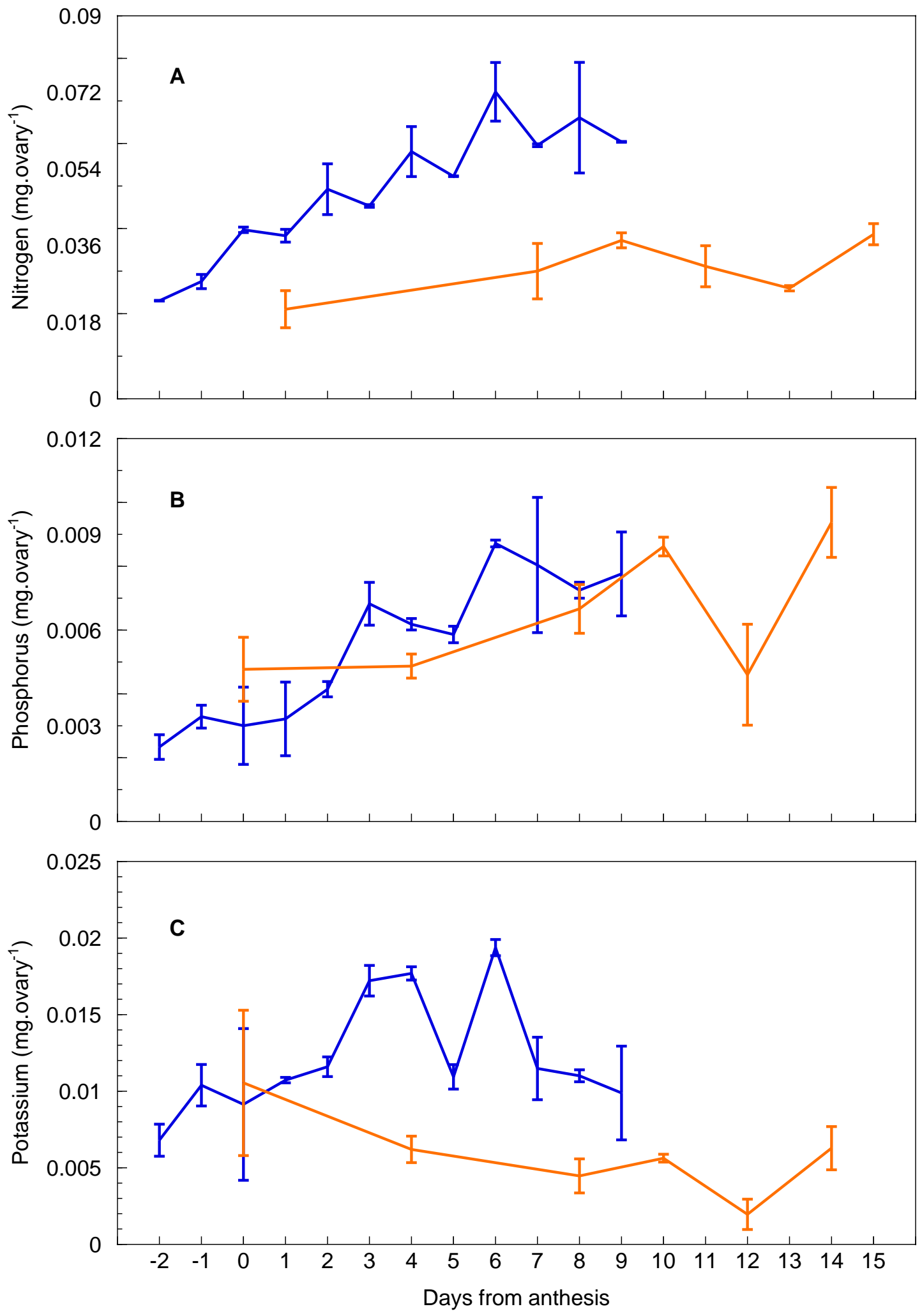

Fig. 2.8. Changes in Nitrogen (A), Phosphorus (B), and Potassium (C) content of ovaries during flower development and senescence of Mitchell ( - ) and CaMV35setr1-1(-). 

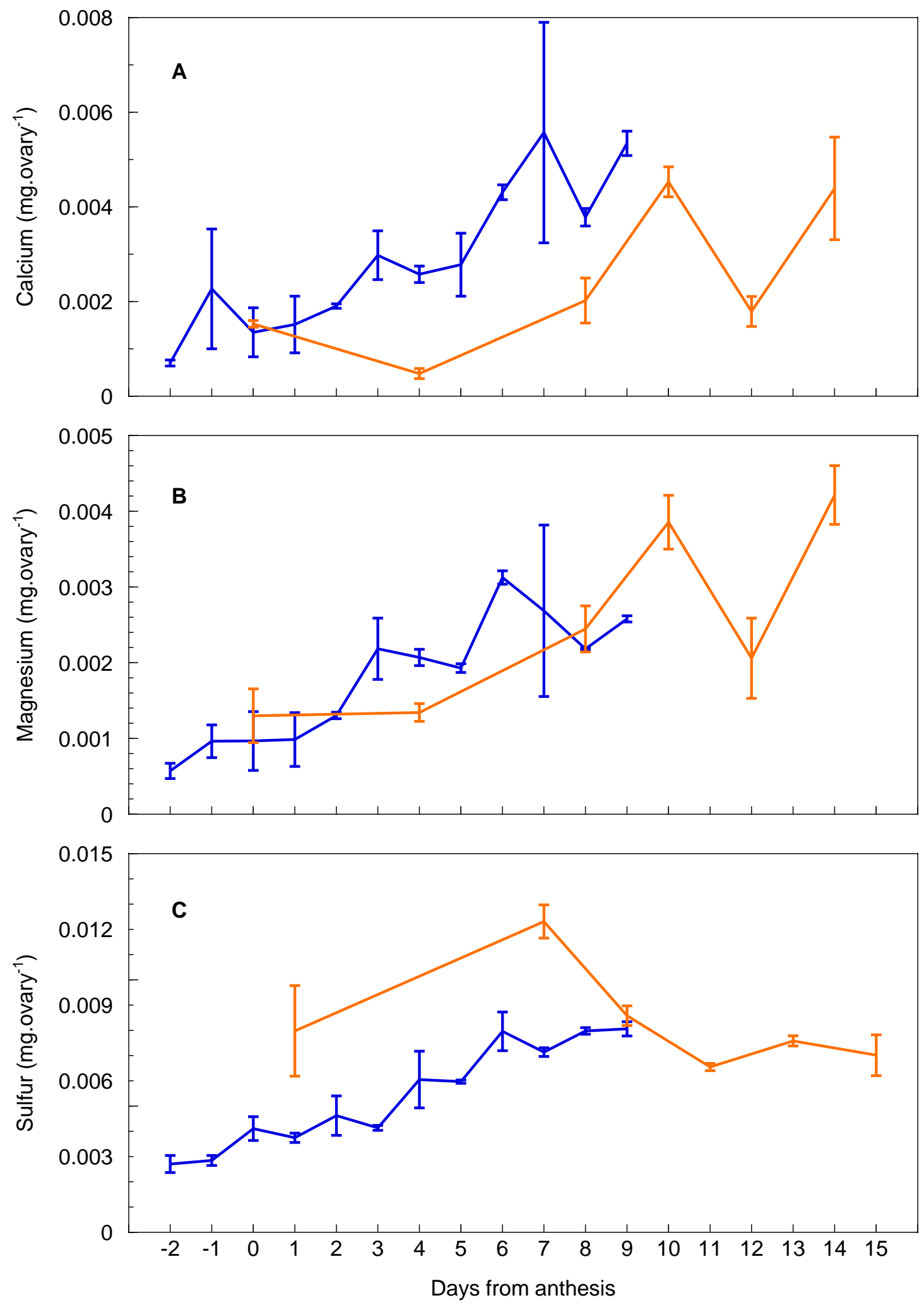

Fig. 2.9. Changes in Calcium (A), Magnesium (B), and Sulfur (C) content of ovaries during flower development and senescence of Mitchell (-) and CaMV35Setr1-1 (-). 

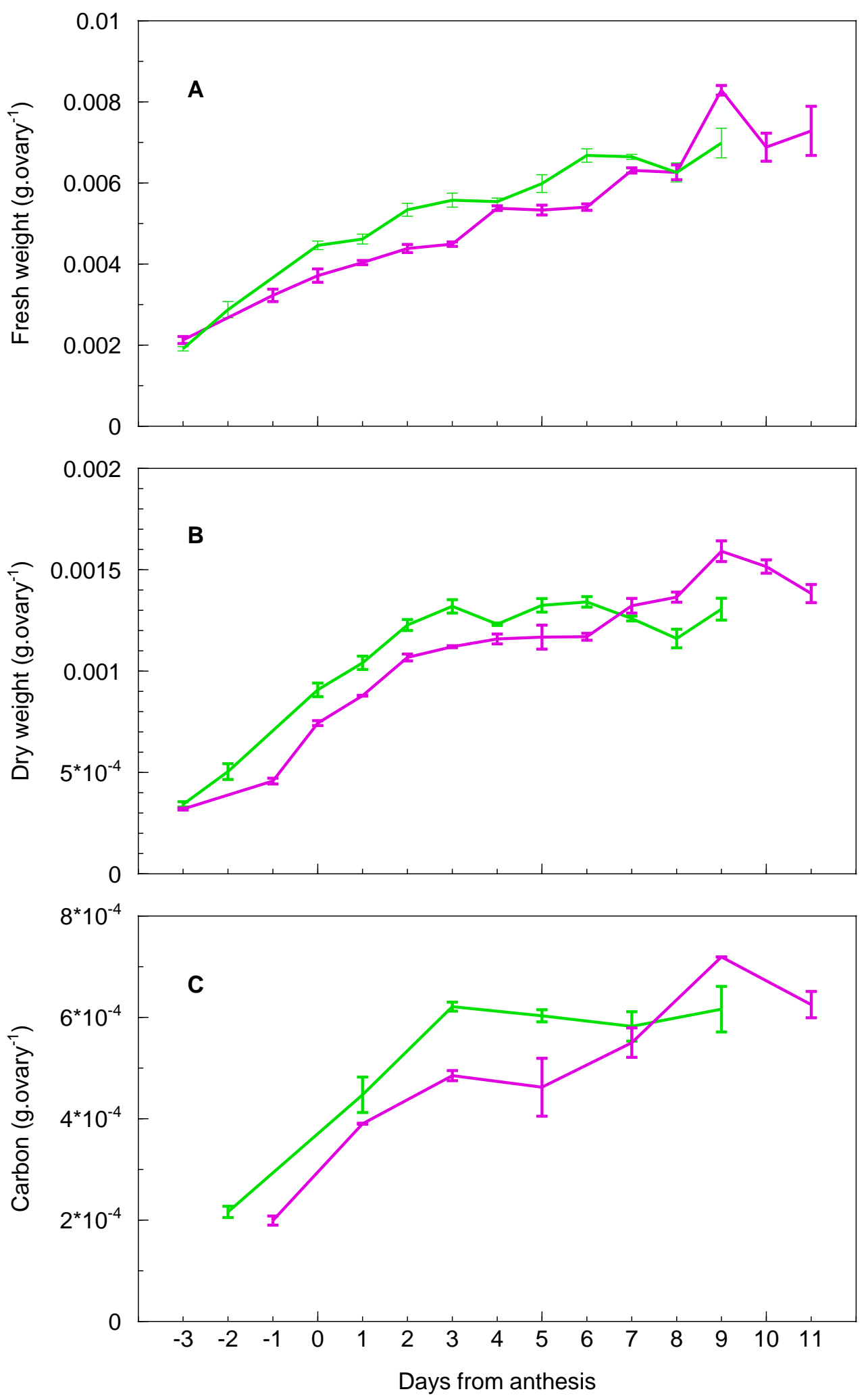

Fig. 2.10. Changes in Fresh weight (A), Dry weight (B), and Carbon content $(C)$ of ovaries during flower development and senescence of V26 (-) and SAG12-IPT (-). 



Fig. 2.11. Changes in Nitrogen (A), Phosphorus (B), and Potassium (C) content of ovaries during flower development and senescence of V26 (-) and SAG12-IPT (-). 

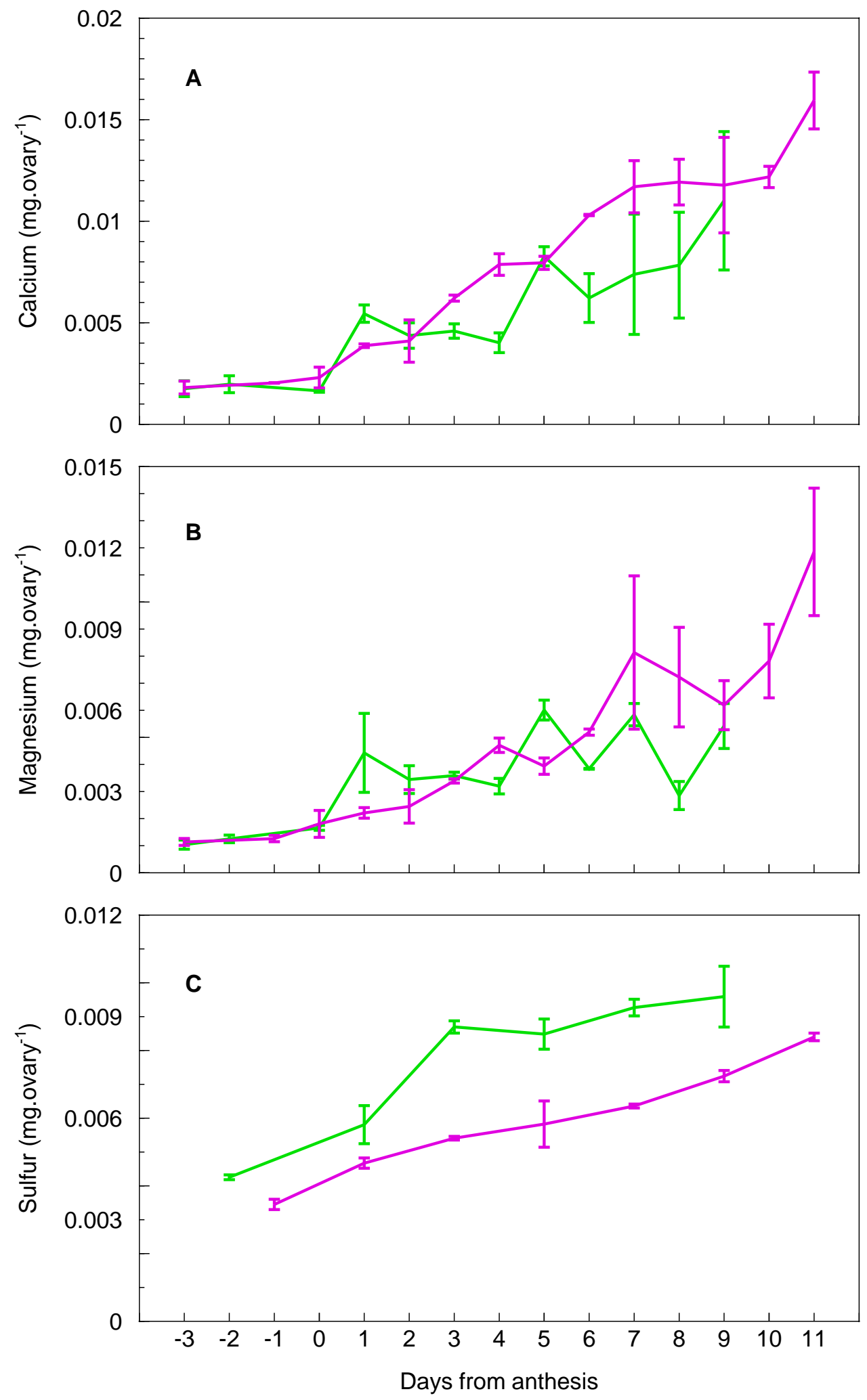

Fig. 2.12. Changes in Calcium (A), Magnesium (B), and Sulfur (C) content of ovaries during flower development and senescence of V26 $(-)$ and SAG12-IPT (-). 

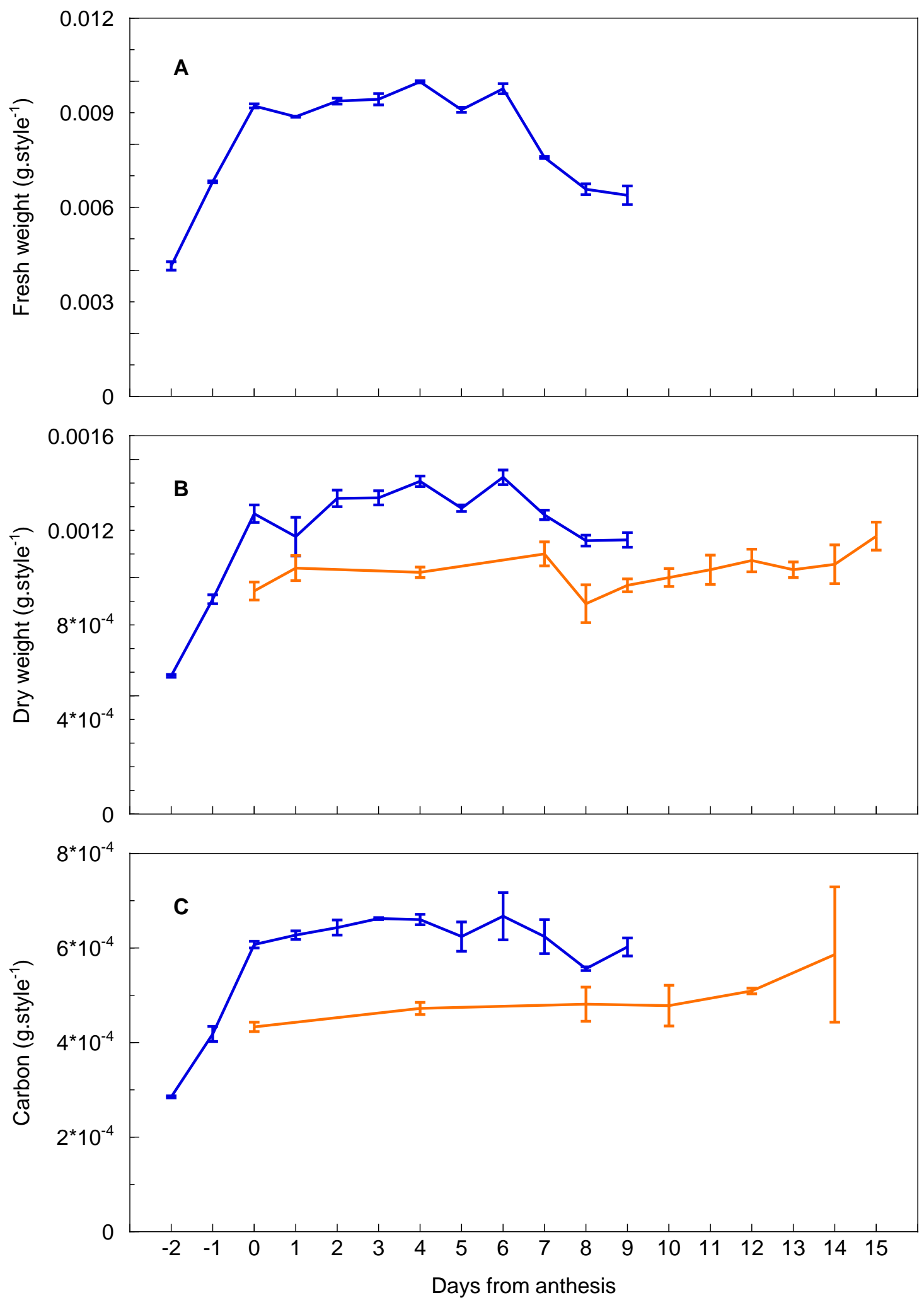

Fig. 2.13. Changes in Fresh weight (A), Dry weight (B), and Carbon content (C) of styles during flower development and senescence of Mitchell $(-)$ and CaMV35Setr1-1 (-). 



Fig. 2.14. Changes in Nitrogen (A), Phosphorus (B), and Potassium (C) content of styles during flower development and senescence of Mitchell (-) and CaMV35Setr1-1 (-). 

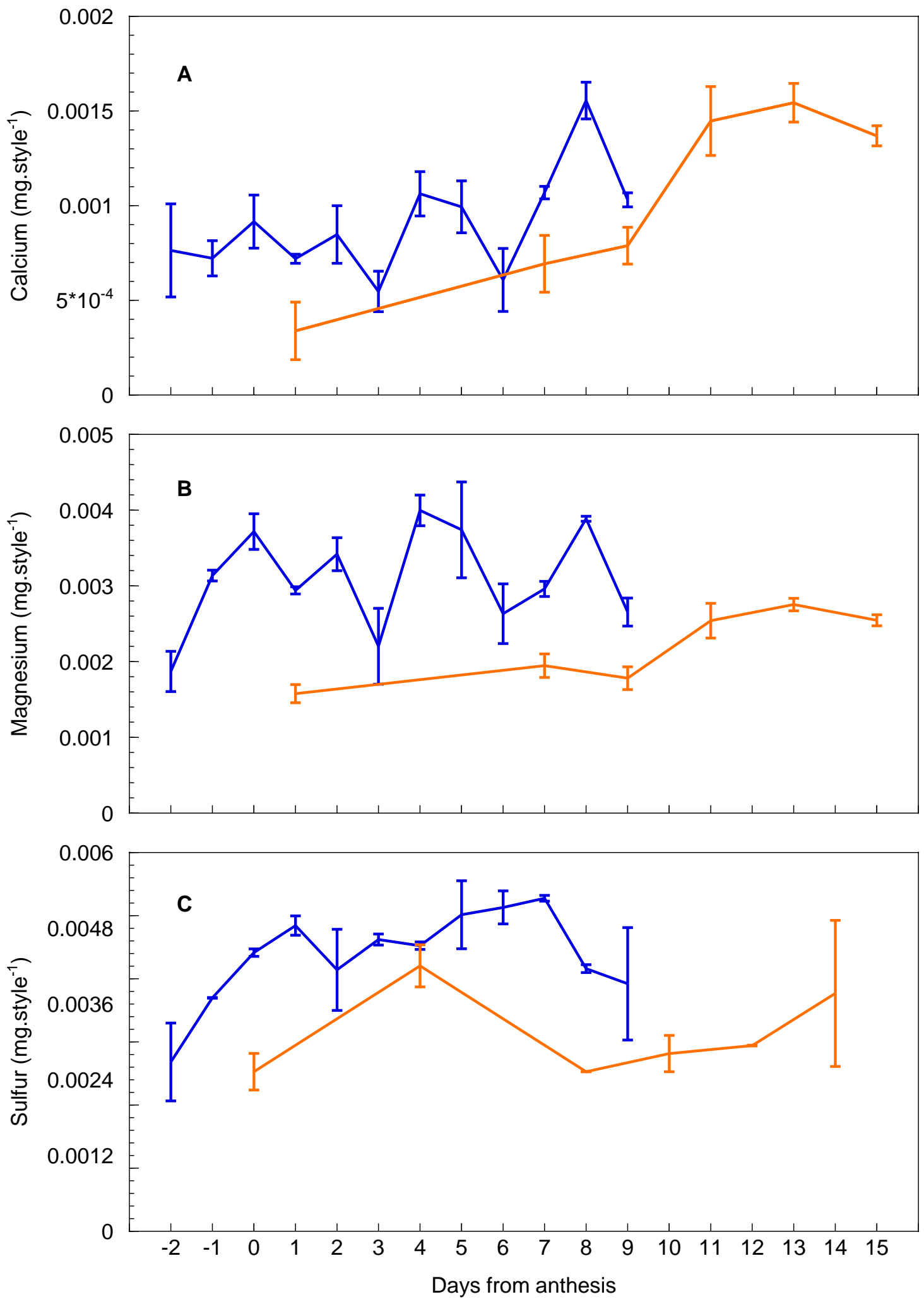

Fig. 2.15. Changes in Calcium (A), Magnesium (B), and Sulfur (C) content of styles during flower development and senescence of Mitchell (-) and CaMv35Setr1-1(-). 

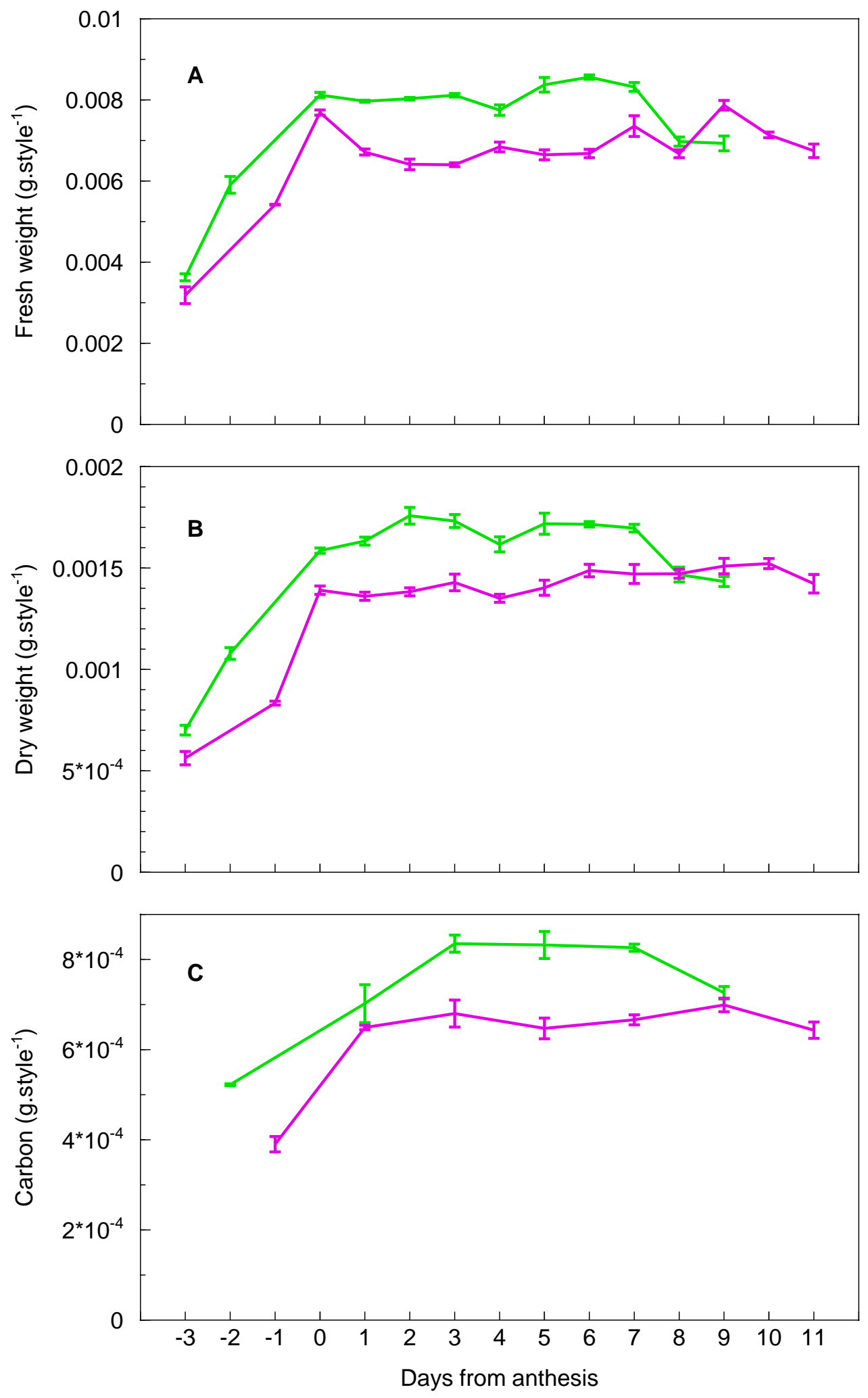

Fig. 2.16. Changes in Fresh weight (A), Dry weight (B), and Carbon $(C)$ content of styles during flower development and senescence of V26 (-) and SAG12-IPT (-). 

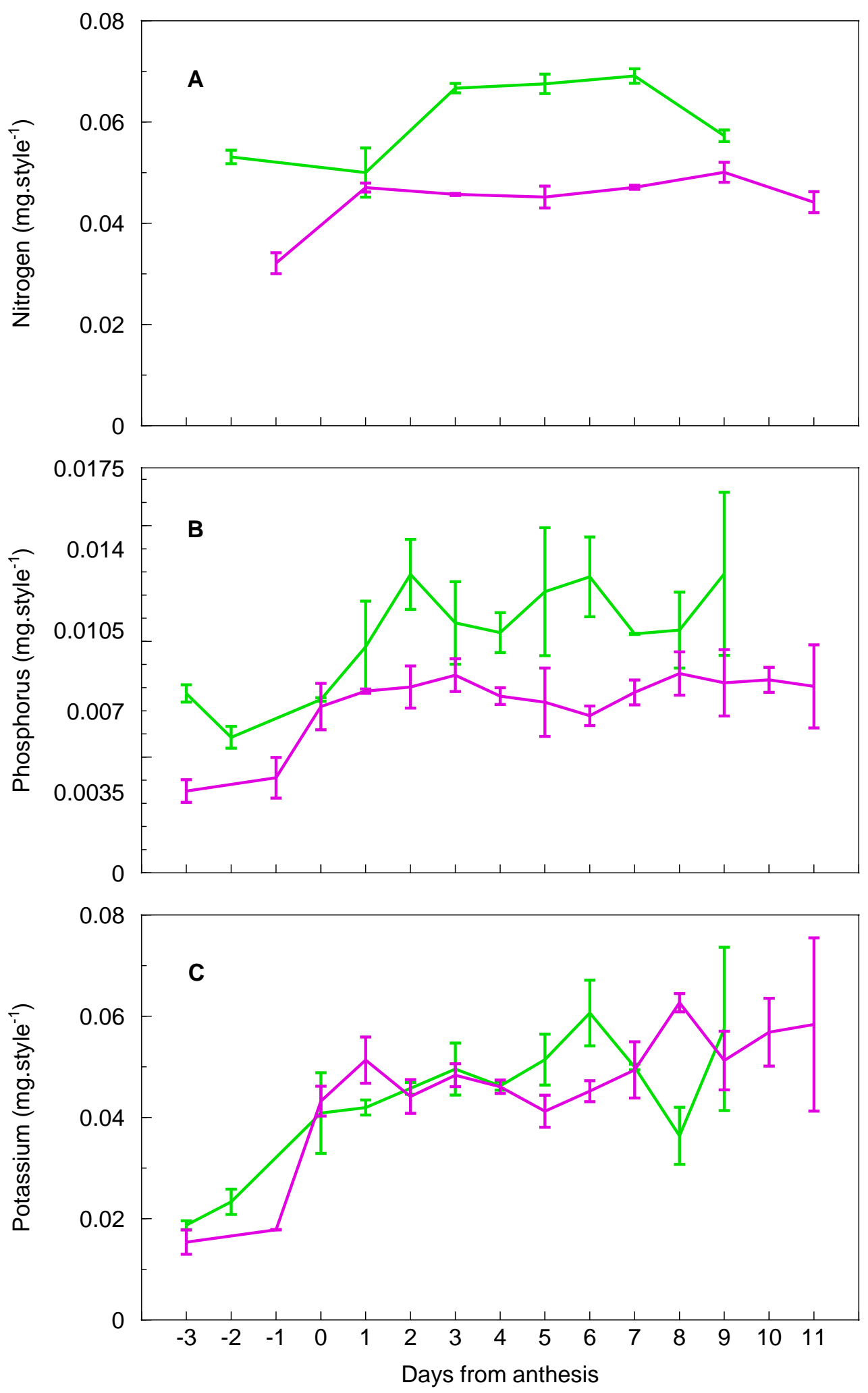

Fig. 2.17. Changes in Nitrogen (A), Phosphorus (B), and Potassium (C) content of styles during flower development and senescence of V26 (-) and SAG12-IPT (-). 

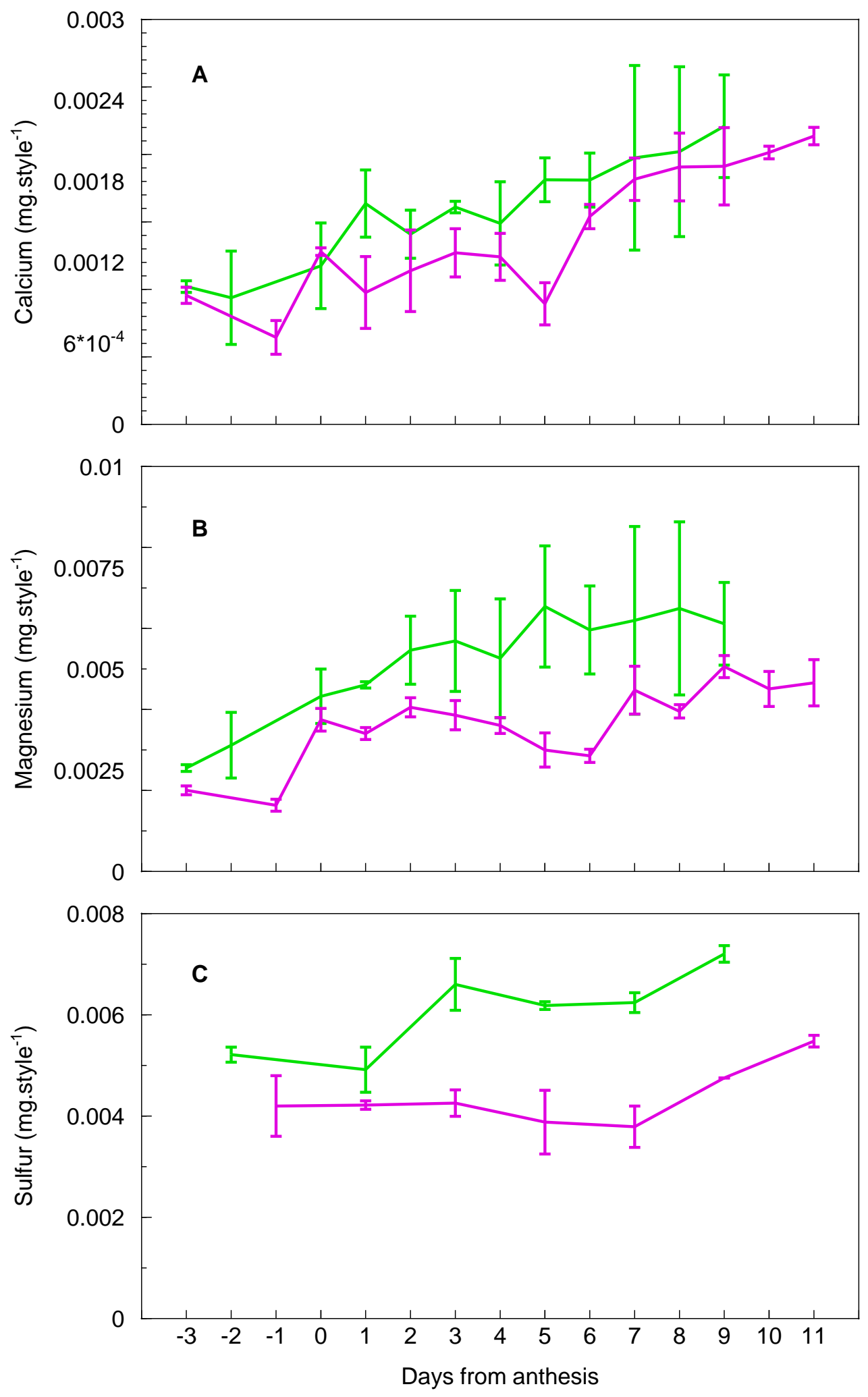

Fig. 2.18. Changes in Calcium (A), Magnesium (B), and Sulfur (C) content of styles during flower development and senescence of V26 (-) and SAG12-IPT (-). 


\section{CHAPTER THREE: Pollination-Induced Senescence}

\section{Introduction}

Pollination leads to the onset of fruit development and the senescence of floral organs that become obsolete after pollination has occurred, such as corollas and styles. In many flowers, the initial response to pollination is an early increase in ethylene production by the stigma that is often followed by increased ethylene production from ovaries and petals (Jones and Woodson, 1999). Pollination serves to accelerate ethylene biosynthesis and developmental changes observed during the natural senescence of agerelated flowers (Stead, 1992). In contrast, flowers that are ethylene-insensitive do not exhibit pollination-induced corolla senescence (Jones and Woodson, 1997; O’Neill et al., 1993; Wilkinson et al., 1997).

Pollen germinates on the stigma, but subsequent developmental responses occur in the ovary and perianth segments, indicating that a pollination signal must move from the stigma to other floral organs. The source of this translocatable pollination signal remains unclear, but its presence implicates the involvement of an interorgan messenger of pollination (O’Neill et al., 1993). The pollinated stigma and subsequent signal transduction, give rise to the induction of developmental processes within the flower including ovule differentiation, ovary development, corolla senescence, and the remobilization of nutrients from senescing structures to developing structures like the ovary (Stead, 1992; Larsen et al, 1993; O’Neill et al., 1993).

\section{Materials and Methods}

For this experiment on pollination-induced senescence, only Petunia x hybrida cv. Mitchell was used as plant material. Greenhouse production, experimental design, 
and statistical analyses were conducted using the same steps as the experiment for agerelated senescence (see Chapter 2). However, in this experiment on pollination-induced senescence, the flowers were pollinated at anthesis. Flower collections were made at hourly intervals following pollination $(9,24,33,48,72 \mathrm{hr})$ as opposed to the daily intervals during age-related senescence. Two flower bud stages, occurring prior to anthesis, were also collected (-24 and $-48 \mathrm{hr})$.

\section{Results}

\subsection{Mitchell corollas}

3.11. Fresh and dry weight. Corolla fresh weight increased at a rate of $0.003 \mathrm{~g} \cdot \mathrm{h}^{-1}$ until pollination, and then decreased at a rate of $0.0017 \mathrm{~g} \cdot \mathrm{h}^{-1}$ through senescence (Fig. 3.1A). Dry weight increased by three-fold in the 48 hours leading up to anthesis. After pollination, dry weight losses occurred at a rate of 0.00025 g.h $\mathrm{h}^{-1}$ (Fig. 3.1B).

3.12. Carbon. Changes in carbon content followed a similar pattern to changes in dry weight (Fig. 3.1C). However, the rate at which the amount of carbon decreased following pollination was slower with a rate of $0.00011 \mathrm{~g} \cdot \mathrm{h}^{-1}$, when compared to changes in dry weight.

3.13. Macronutrients. Phosphorus content increased by nearly $75 \%$ immediately following pollination through 9 hours after pollination (Fig. 3.2B). After 9 hours, phosphorus declined three-fold through senescence. Patterns of changes in calcium and magnesium contents were similar to phosphorus, except that contents of these elements increased by nearly $90 \%$ from pollination through 9 hours, followed by a decrease through senescence of nearly $20 \%$ and $40 \%$, respectively (Fig. 3.3A and B). Nitrogen, sulfur, and potassium contents increased steadily in the hours prior to anthesis, remained 
fairly constant until 24 hours after pollination, and were followed by a steady decrease through senescence (Fig. 3.2A and C; 3.3C).

\subsection{Mitchell ovaries}

3.21. Fresh and dry weight. Ovary fresh weight increased from pollination through 33 hours by $75 \%$, followed by another $230 \%$ increase through senescence of the flower (Fig. 3.4A). Dry weight increases followed a similar pattern and showed an increase of $65 \%$ following pollination through 33 hours after pollination, followed by a 155\% increase through completed flower senescence (Fig. 3.4B).

3.22. Carbon. Ovary carbon content showed a similar pattern to dry weight changes and increased by nearly 300\% from pollination through senescence (Fig. 3.4C).

3.23. Macronutrients. All macronutrient concentrations increased from 48 hours prior to anthesis through completed floral senescence, although the pace increased from 33 hours through senescence (Fig. 3.5 and 3.6). Following pollination, sulfur, calcium, nitrogen, potassium, and magnesium contents increased by 160\%, 240\%, 280\%, 380\%, and $450 \%$ respectively (Fig. 3.5A and C; 3.6A-C).

\subsection{Mitchell styles}

3.31. Fresh and dry weight. Style fresh and dry weight increased until 9 hours after pollination, and then decreased slightly through anthesis (3.7A and B).

3.32. Carbon. Changes in style carbon content followed a similar pattern to changes in dry weight (Fig. 3.7C). An increase in carbon content was observed until 9 hours after pollination, subsequently decreasing slightly through senescence.

3.33. Macronutrients. Potassium, calcium, and magnesium contents remained fairly constant following pollination, except for the abrupt decreases noted between 33 
and 48 hours (Fig. 3.8C; 3.9A and B). Nine hours after pollination, nitrogen content of styles had increased by $30 \%$, to 0.064 g.corolla ${ }^{-1}$, where it remained relatively constant through completed floral senescence (Fig. 3.8A). Phosphorus content increased for 24 hours following pollination, then decreased by 35\% through senescence (Fig. 3.8B).

\section{Discussion}

Pollination-induced senescence of Mitchell is distinguished by only two developmental phases: growth (-48 hours to 0 hours, or anthesis) and senescence (0 hours to 72 hours) (Table 3.1). The maintenance phase observed in age-related senescence is nonexistent in pollination-induced senescence due to the effect of pollination on the acceleration of senescence.

In Mitchell, the response to pollination is delayed and occurs 9-24 hours following pollination in corollas and styles, with corollas exhibiting significant remobilization of nutrients beginning at this time and continuing through senescence (Fig. 3.1-3.3 and 3.7-3.9). In Petunia inflata flowers, pollination-induced ethylene production has been shown to occur in two peaks with the first peak at 3 hours and the second at 18 hours after pollination (Singh et al., 1992), suggesting that the onset of nutrient remobilization from corollas may be related to the onset of the second surge of ethylene production following pollination.

In Mitchell, an increase in fresh weight, dry weight, and macronutrient contents of ovaries is concomitant with a decrease of these same measurements in corollas (Fig. 3.1A and 3.4A). The same inverse relationship has also been observed for fresh weight, dry weight, nitrogen, and phosphorus in the perianth and ovary of orchid (Hew et al., 1989). However, the decrease in macronutrient concentration from Mitchell corollas far exceeds 
the increase in macronutrient concentrations in the ovaries, indicating that a large portion of corolla nutrients go back into other areas of the plant. A similar conclusion was derived from a study on carnation flowers, which showed that the removal of petals the day of flower harvest did not reduce the accumulation of dry matter in the ovary (Mor et al., 1980), indicating that redistribution of metabolites from the senescing petals does not contribute substantially to ovary growth (Borochov and Woodson, 1989). In Mitchell ovaries, the macronutrient content increases dramatically after 33 hours, coinciding with growth of the ovary (Fig. 3.3 and 3.6). It is has been suggested that the increased cell activity in the ovary following the action of ethylene could serve as an active sink for the influx of materials to the ovary (Hew et al., 1989).

It is generally accepted that calcium is an immobile element, although in soybean calcium is remobilized from the leaves (Mauk and Nooden, 1992). In Mitchell, calcium is remobilized from the corollas 9 hours after pollination and also from styles, though at a slower pace (Fig. 3.3B and 3.9B), suggesting that calcium mobility is species dependent.

The manner in which inorganic and organic materials move out of floral organs is unknown, but may be the result of increased permeability of cell membranes caused by ethylene (Hanson and Kende, 1975). The rate at which changes in macronutrient content occurs is higher in pollination-induced senescence than in age-related senescence, hence the lack of a maintenance phase. Indeed, further studies on changes in macronutrient content among floral organs are needed and will help to further elucidate the role of these nutrients in flower senescence. 

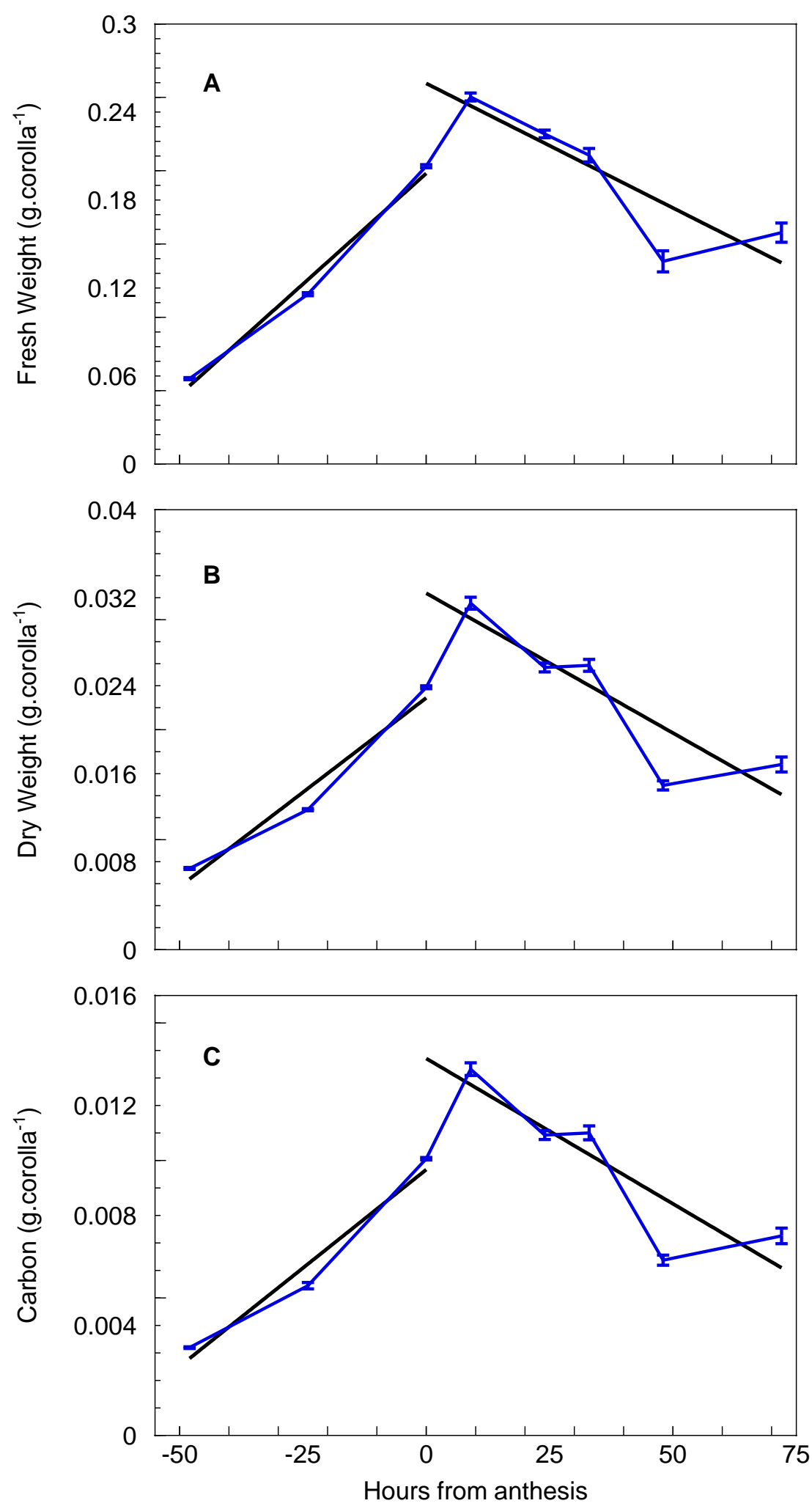

Fig. 3.1. Changes in Fresh weight (A), Dry weight (B), and Carbon content $(C)$ of corollas during flower development and senescence of Mitchell (-). 



Fig. 3.2. Changes in Nitrogen (A), Phosphorus (B), and Potassium (C) content of corollas during flower development and senescence of Mitchell (-). 

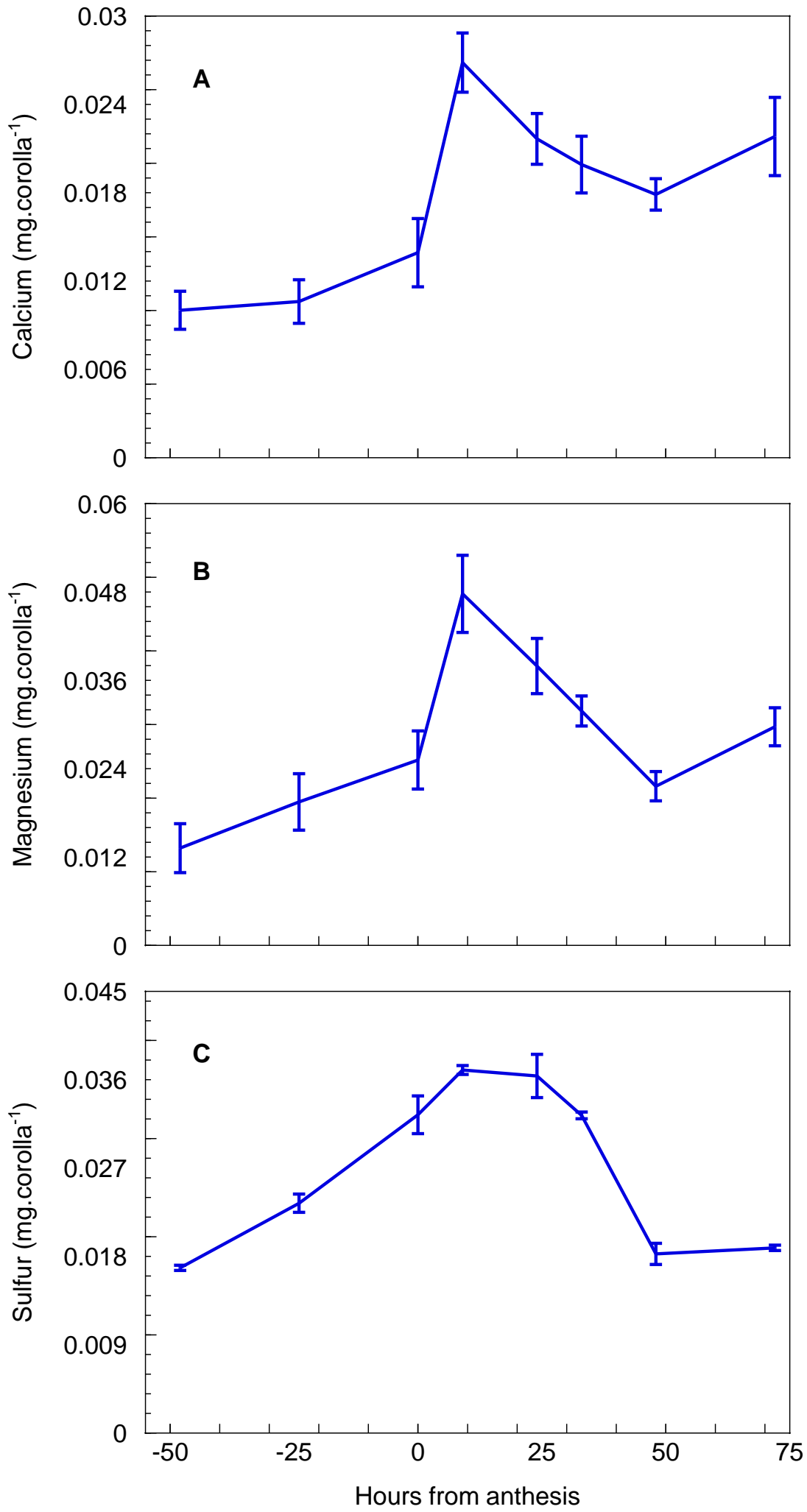

Fig. 3.3. Changes in Calcium (A), Magnesium (B), and Sulfur $(C)$ content of corollas during flower development and senescence of Mitchell (-). 

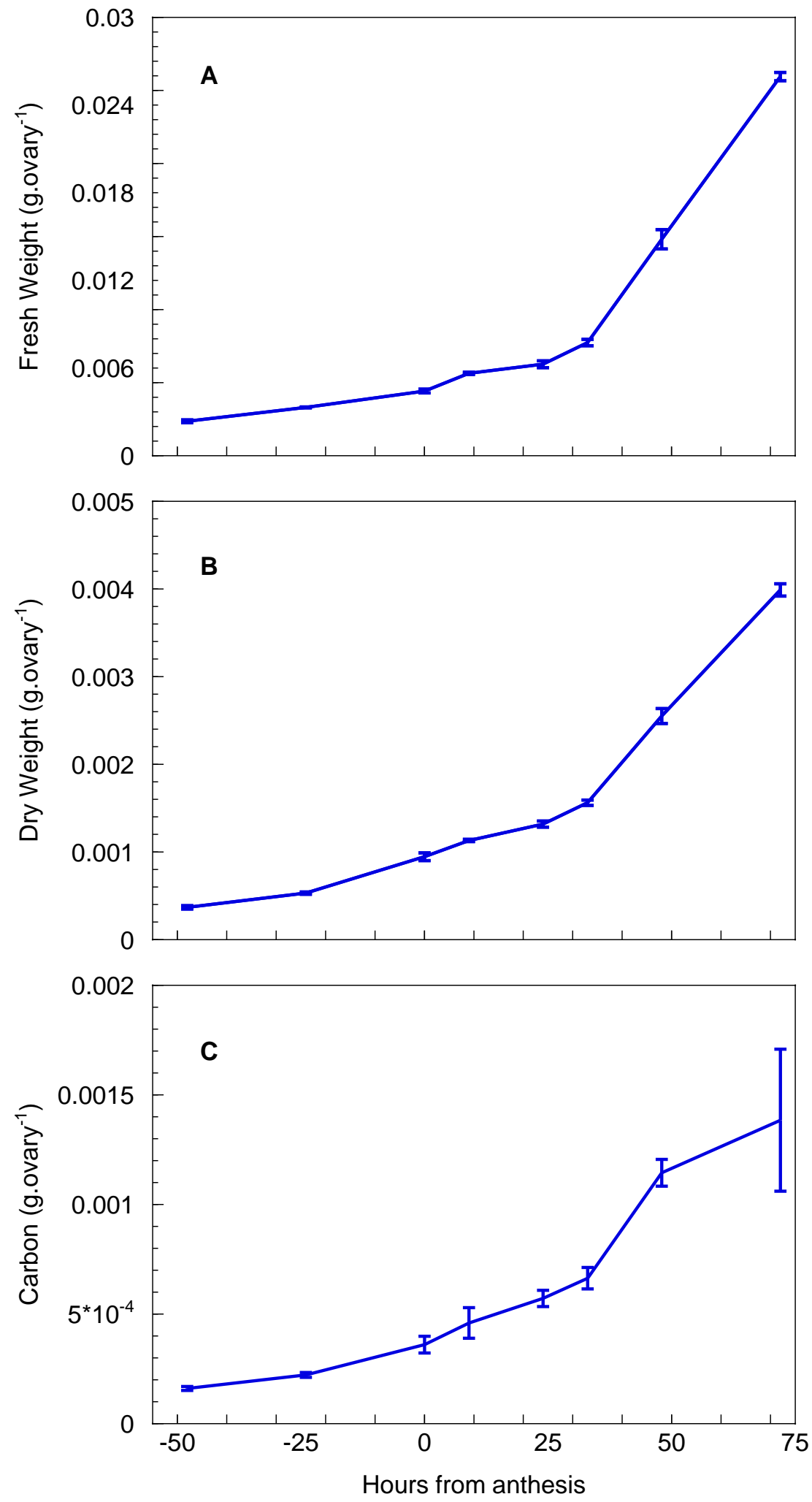

Fig. 3.4. Changes in Fresh weight (A), Dry weight (B), and Carbon content $(C)$ of ovaries during flower development and senescence of Mitchell (-). 

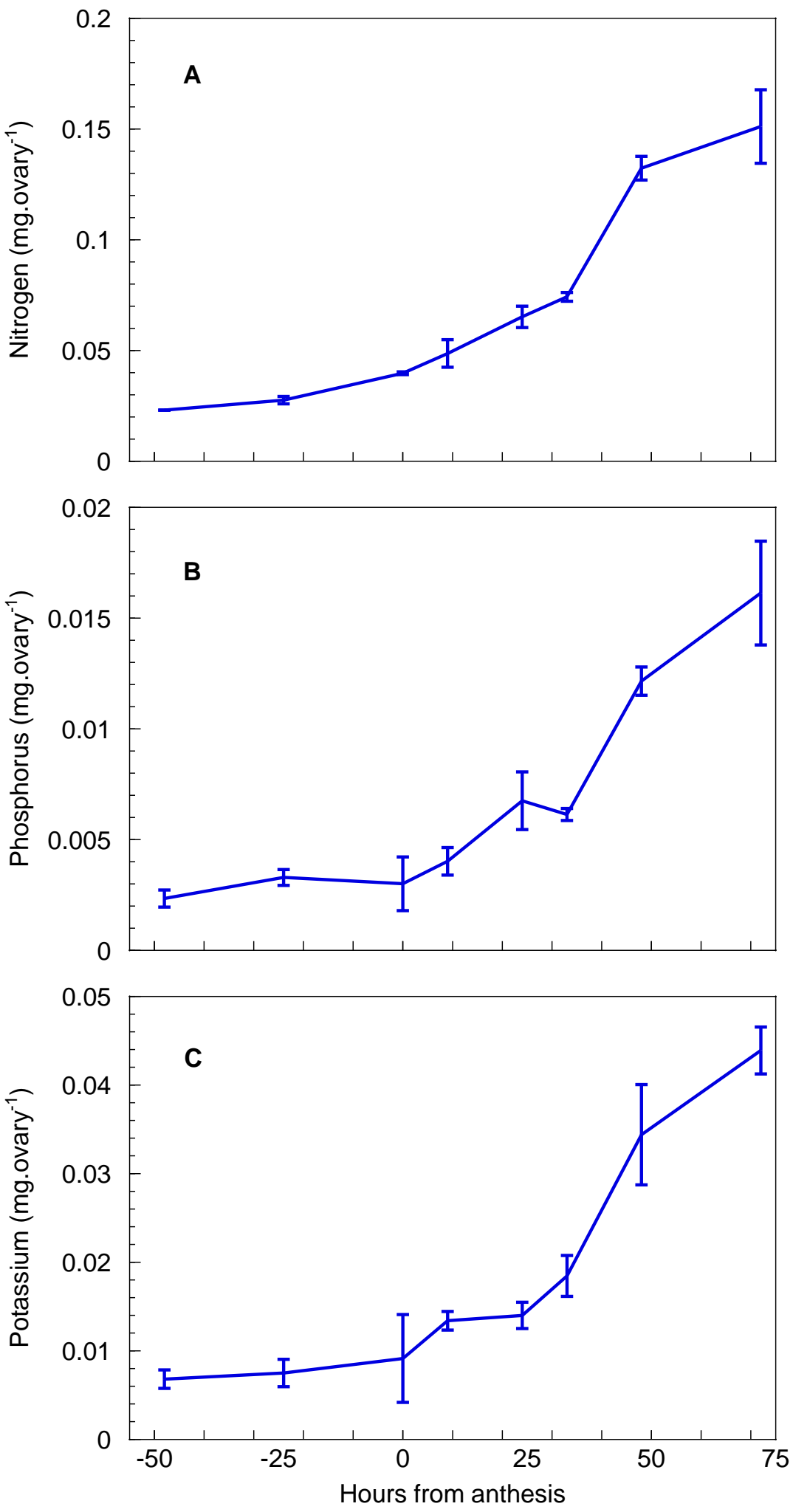

Fig. 3.5. Changes in Nitrogen (A), Phosphorus (B), and Potassium (C) of ovaries during flower development and senescence of Mitchell (-). 

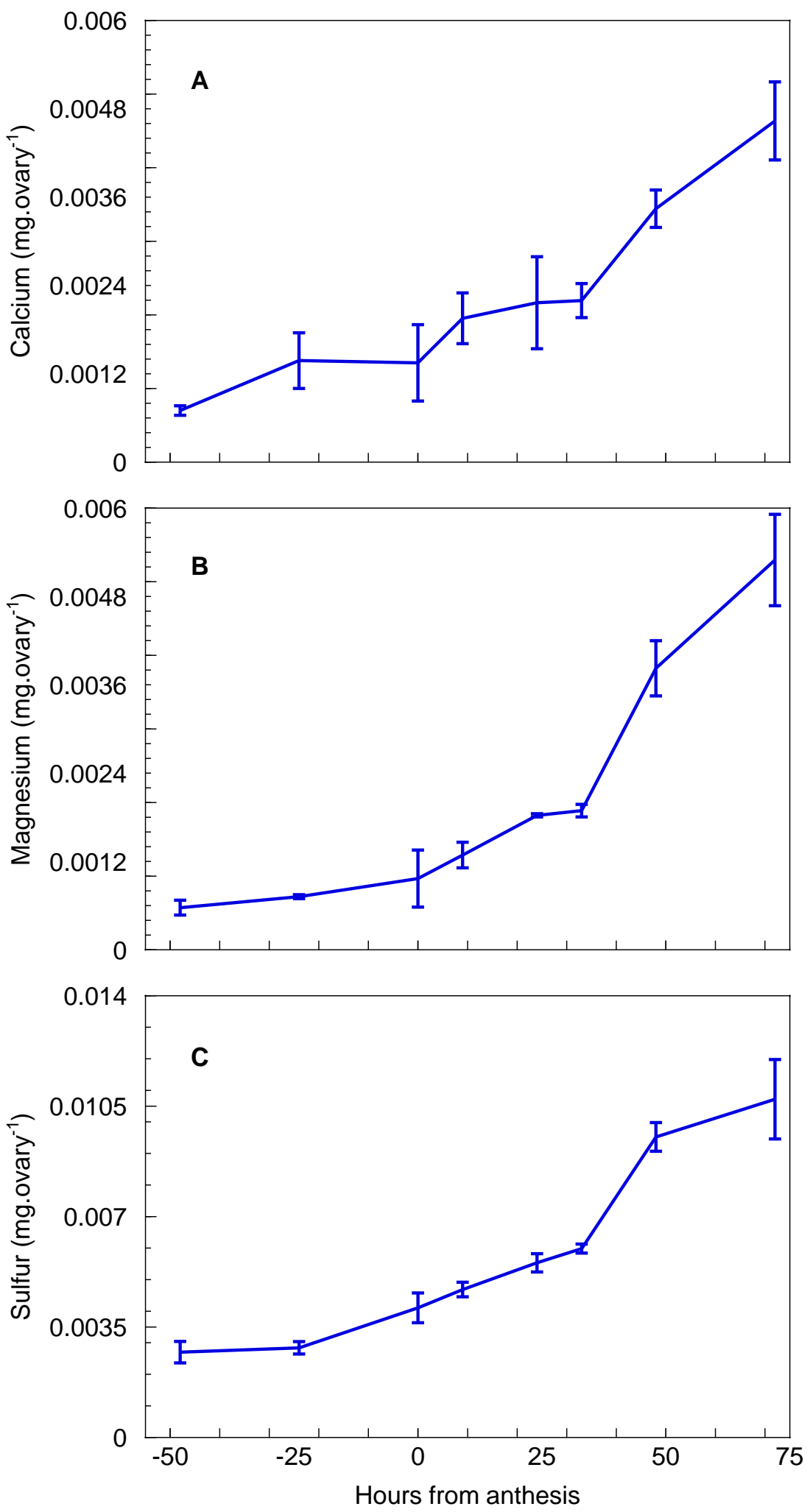

Fig. 3.6. Changes in Calcium (A), Magnesium (B), and Sulfur (C) of ovaries during flower development and senescence of Mitchell (-). 

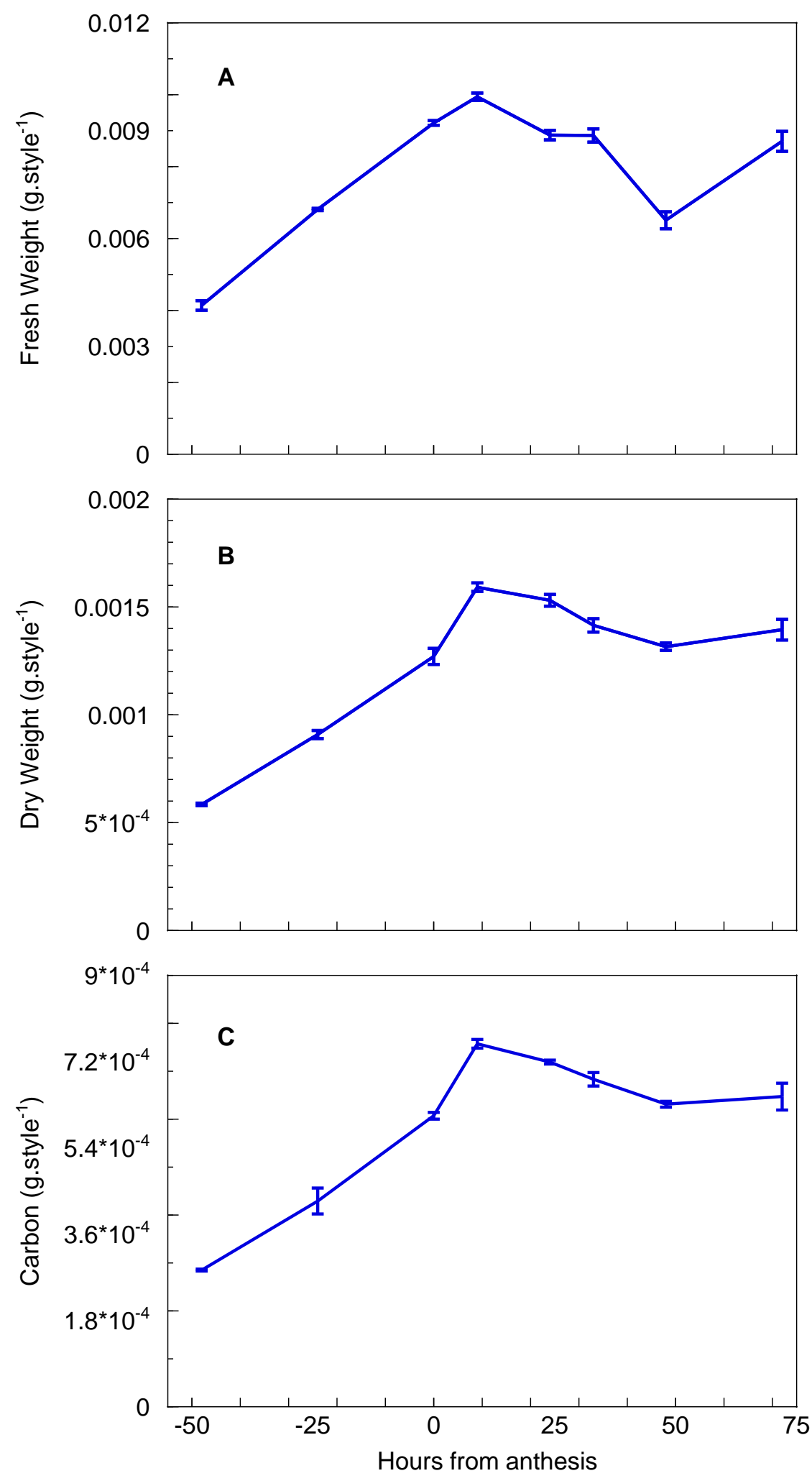

Fig. 3.7. Changes in Fresh weight (A), Dry weight (B), and Carbon content $(C)$ of styles during flower development and senescence of Mitchell (-). 

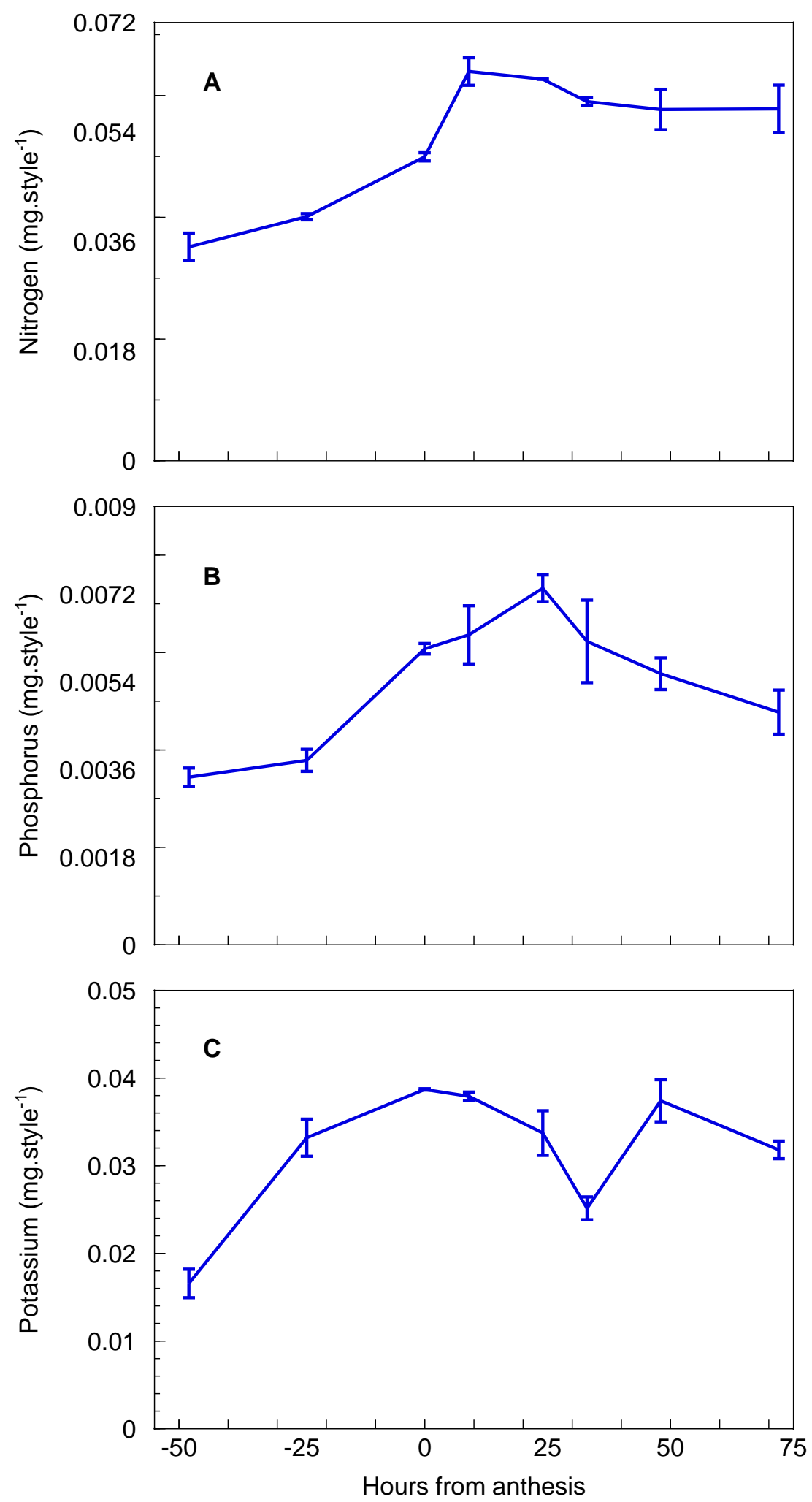

Fig. 3.8. Changes in Nitrogen (A), Phosphorus (B), and Potassium (C) content of styles during flower development and senescence of Mitchell (-). 



Fig. 3.9. Changes in Calcium (A), Magnesium (B), and Sulfur $(C)$ content of styles during flower development and senescence of Mitchell (-). 


\section{LITERATURE CITED}

Abeles, F.B., P.W. Morgan, and M.E. Salveit, Jr. 1992. Ethylene in plant biology. Academic Press, San Diego.

Adam, Z., A. Borochov, S. Mayak, and A.H. Halevy. 1983. Correlative changes in sucrose uptake, ATPase activity and membrane fluidity in carnation petals during senescence. Physiol. Plant. 58:257-262.

Adams, D.O. and S.F. Yang. 1979. Ethylene biosynthesis: Identification of 1aminocyclopropane-1-carboxylic acid as an intermediate in the conversion of methionine to ethylene. Proc. Nat. Acad. Sci. USA. 76:170-174.

Ashman, T.L. and D.J. Schoen. 1994. How long should flowers live? Nature. 371:788-790.

Ashman, T.L. and D.J. Schoen. 1997. The cost of floral longevity in Clarkia tembloriensis: An experimental investigation. Evol. Ecol. 11:289-300.

Bangerth, F. 1979. Calcium-related physiological disorders of plants. Annu. Rev. Phytopathol. 17:97-122.

Beutelmann, P. and H. Kende. 1977. Membrane lipids in senescing flower tissue of Ipomoea tricolor. Plant Physiol. 59:888-893.

Bieleski, R.L. 1995. Onset of phloem export from senescent petals of daylily. Plant Physiol. 109:557-565.

Bieleski, R.L. 2000. The bigger picture-phloem seen through horticultural eyes. Aust. J. Plant Physiol. 27:615-624.

Bieleski, R.L. and M.S. Reid. 1992. Physiological changes accompanying senescence in the ephemeral daylily flower. Plant Physiol. 98:1042-1049.

Bieleski, R.L. and R.J. Redgwell. 1985. Sorbitol versus sucrose as photosynthesis and translocation products in developing apricot leaves. Aust. J. Plant. Physiol. 12:657-668.

Borochov, A. and R. Faiman-Weinber. 1984. Biochemical and biophysical changes in plant protoplasmic membranes during senescence. What's New in Plant Physiol. 15:1-4.

Borochov, A., H. Speiegelstein, and R. Porat. 1995. Membrane lipids involved in the regulation of flower senescence. Acta Hortic. 405:240-245.

Borochov, A. and W.R. Woodson. 1989. Physiology and biochemistry of flower petal senescence. Hort Reviews 11:15-43.

Brantjes, N.B.M. 1973. Sphingophilous flowers, function of their scent. Pollin. Disp. 27-46.

Brown, J.H., J.A. Chambers, and J.E. Thompson. 1991. Acyl chain and head group regulation of phospholipid catabolism in senescing carnation flowers. Plant Physiol. 95:909-916.

Brown, J.H., D.V. Lynch, and J.E. Thompson. 1987. Molecular species specificity of phospholipid breakdown in microsomal membranes of senescing carnation flowers. Plant Physiol. 85:679-683.

Bui, A.Q. and S.D. O’Neill. 1998. Three 1-aminocyclopropane-1-carboxylate synthase genes regulated by primary and secondary pollination signals in orchid flowers. Plant Physiol. 116:419-428.

Bukovac, M.J. and S.H. Wittwer. 1957. Absorption and mobility of foliar applied nutrients. Plant Physiol. 32:428-435.

Chang, H., M.L. Jones, G.M. Banowetz, and D.G. Clark. 2003. Overproduction of cytokinins in petunia flowers transformed with $\mathrm{P}_{\mathrm{SAG} 12}$-IPT delays corolla senescence and decreases sensitivity to ethylene. Plant Physiol. 132:2174-2183.

Clement, C., M.B. Burrus, and J-C. Audran. 1996. Floral organ growth and carbohydrate content during pollen development in Lilium. Am. J. Bot. 83(4):459-469.

Cook, D., M. Rasche, and W. Eisinger. 1985. Regulation of ethylene biosynthesis and action in cut carnation flower senescence by cytokinins. J. Am. Soc. Hort. Sci. 110:24-27.

Dervinis, C., D.G. Clark, J.E. Barrett, and T.A. Nell. 1998. Prevention of leaf senescence in petunia via genetic transformation with SAG-IPT. Proc. Fla. State Hort. Soc. 11:12-15. 
Drossopoulos, J.B., G.G. Houchaji, and D.L. Bouranis. 1996. Seasonal dynamics of mineral nutrient by walnut reproductive organs. J. Plant. Nutr. 19:421-434.

Eisinger, W. 1977. Role of cytokinins in carnation flower senescence. Plant Physiol. 59:707-709.

Epstein, E. 1972. Mineral nutrient of plants: principles and perspectives. Wiley, New York.

Fahnestock, G.W. 1858. Memoranda of the effect of carburetted hydrogen gas upon a collection of exotic plants. Proc. Acad. Sci. Nat. Sci. Phila. 1:118-134.

Ferguson, I.B. and B.K. Drobak. 1988. Calcium and the regulation of plant growth and senescence. HortScience. 23:262-266.

Flowers, T.J. and A.R. Yeo. 1992. Solute transport in plants. Blackie, New York.

Gan, S., and R.M. Amasino. 1995. Inhibition of leaf senescence by autoregulated production of cytokinin. Science. 270:1986-1988.

Gessner, F. 1948. Stoffwanderungen in bestaubten Orchideenbluten. Biol. Zentralbl. 67:457-477.

Gilissen, L.J.W. 1976. The role of the style as a sense-organ in relation to wilting of the flower. Planta. 131:201-202.

Gilissen, L.J.W. 1977. Style-controlled wilting of the flower. Planta. 133:275-280.

Gilissen, L.J.W., and F.A. Hoekstra. 1984. Pollination-induced corolla wilting in Petuna hybrida rapid transfer through the style of a wilting-inducing substance. Plant Physiol. 75:496-498.

Gubrium, E., D.J. Clevenger, D.G. Clark, J.E. Barrett, and T.A. Nell. 2000. Reproduction and horticultural performance of transgenic ethylene-insensitive petunias. J. Amer. Soc. Hort. Sci. 125:277-281.

Hall, S.M. and D.A. Baker. 1972. The chemical composition of Ricinus phloem exudates. Planta. 106:131-140.

Hall, I.V. and F.R. Forsyth. 1967. Production of ethylene by flowers following pollination and treatments with water and auxin. Can. J. Bot. 45:1163-1166.

Halevy, A.H. 1986. Pollination-Induced corolla senescence. Acta Hort. 181:25-32.

Halevy, A.H., D.R. Dilley, and S.H. Wittwer. 1966. Senescence inhibition and respiration induced by growth retardants and ${ }^{6} \mathrm{~N}$-benzyladenine. Plant Physiol. 41:1085-1089.

Halevy, A.H., and S. Mayak. 1979. Senescence and postharvest physiology of cut flowers. Part 1. Hort. Rev. 1:204-236.

Halevy, A.H. and S. Mayak. 1981. Senescence and postharvest physiology of cut flowers, part 2. Hort. Rev. 3:59-143.

Han, S.S., A.H. Halevy, and M.S. Reid. 1991. The role of ethylene and pollination in petal senescence and ovary growth of brodiaea. J. Amer. Soc. Hort. Sci. 116(1):68-72.

Hanson, A.D., and H. Kende. 1975. Ethylene enhanced ion and sucrose efflux in morning glory flower tissue. Plant Physiol. 55:663-669.

Harrison, C.R., and J. Arditti. 1976. Post pollination phenomena in orchid flowers. VII. Phosphate movement among floral segments. Am. J. Bot. 63:911-918.

Hew, C.S., S.C. Tan, T.Y. Chin, and T.K. Ong. 1989. Influence of ethylene on enzyme activities and mobilization of materials in pollinated Arachnis orchid flowers. J. Plant Growth Regul. 8:121-130.

Hill, J. 1980. Remobilization of nutrients from leaves. J. Plant Nutr. 2:407-444.

Himelblau, E. and R.M. Amasino. 2001. Nutrients mobilized from leaves of Arabidopsis thaliana during leaf senescence. J. Plant Physiol. 158:1317-1323.

Hocking, P.J. 1994. Dry-matter production, mineral nutrient concentrations, and nutrient distribution and redistribution in irrigated spring wheat. J. Plant Nutr. 17:1289-1308.

Hoekstra, F. and R. Weges. 1986. Lack of control by early pistillate ethylene of the accelerated wilting of Petunia hybrida flowers. Plant Physiol. 80:403-408.

Hsiang, T.H.T. 1951. Physiological and biochemical changes accompanying pollination in orchid flowers. I. General observations and water relations. Plant Physiol. 26:441-455.

Itzhaki, H., A. Borochov, and S. Mayak. 1990. Age-related changes in petal membranes from attached and detached rose flowers. Plant Physiol. 94:1233-1236. 
Jacobson, M., M. Weil, and M.C. Raff. 1997. Programmed cell death in animal development. Cell. 88:347-354.

Jones, S.B. and A.E. Luchsinger. 1986. Plant systematics. McGraw-Hill, New York.

Jones, R. and R. McConchie. 1995. Characteristics of petal senescence in a non-climacteric cut flower. Acta Hortic. 405:216-223.

Jones, M.L. and W.R. Woodson. 1997. Pollination-induced ethylene in carnation: Role of stylar ethylene in corolla senescence. Plant Physiol. 115:205-212.

Jones, M.L. and W.R. Woodson. 1999. Interorgan signaling following pollination in carnations. J. Amer. Soc. Hort. Sci. 124(6):598-604.

Kende, H. 1965. Kinetinlike factors in root exudates of sunflower. Pro. Natl. Acad. Sci. USA. 53:1302-1307.

Kende, H. 1993. Ethylene biosynthesis. Annu. Rev. Plant Physiol. Plant. Mol. Biol. 44:283-307.

Kende, H. and A.D. Hanson. 1976. Relationship between ethylene evolution and senescence in morning-glory tissue. Plant Physiol. 57:523-527.

Kirkby, E.A. 1979. Maximizing calcium uptake by plants. Commun Soil Sci. Plant Anal. 10(12):89-113.

Lalonde, S., M. Tegeder, M. Throne-Holst, W.B. Frommer, and J.W. Patrick. 2003. Phloem loading and unloading of sugars and amino acids. Plant Cell Env. 26:37-56.

Larsen, P., E.J. Woltering, and W.R. Woodson. 1993. Ethylene and interorgan signaling in flowers following pollination. Plant signals in interactions with other organisms; American Society of Plant Physiologists: 112-122.

Lay-Yee, M., A.D. Stead, and M.S. Reid. 1992. Flower senescence in daylily. Physiol. Plant. 86:308-314.

Leopold, A.C. 1961. Senescence in plant development. Science. 134:1727-1732.

Leopold, A.C. 1975. Aging, senescence and turnover in plants. BioScience. 25:659-662.

Leutsek, T. and K. Saito. 1999. Sulfate transport and assimilation in plants. Plant Physiol. 120:637-643.

Linskens, H.F. 1974. Translocation phenomena in the petunia flower after cross- and selfpollination, p. 285-292. In: H.F. Linskens (ed.). Fertilization in higher plants. NorthHolland, Amsterdam, The Netherlands.

Lovell, P.H., P.J. Lovell, and R. Nichols. 1987. The Importance of the stigma in flower senescence in Petunia (Petunia hybrida). Ann. Bot. 60:41-47.

Marschner, H. 1983. General introduction to the mineral nutrition of plants, p. 5-49. In: A. Lauchli and R.L. Bieleski (eds.). Inorganic plant nutrition. Springer-Verlag, New York, N.Y.

Marschner, H. 1995. Mineral nutrition of higher plants. Academic Press, London.

Mauk, C.S., and L.D. Nooden. 1992. Regulation of mineral redistribution in pod-bearing soybean explants. J. Exp. Bot. 43(2):1429-1440.

Mayak, S., A.H. Halevy, M. Katz. 1972. Correlative changes in phytohormones in relation to senescence processes in rose petals. Physiol. Plant. 27:1-4.

Mayak, S., and A.M. Kofranek. 1976. Altering and sensitivity of carnation flowers (Dianthus caryophyllus L.) to ethylene. J. Am. Soc. Hort. Sci. 101:503-506.

Mayak, S., A. Borochov, and T. Tirosh. 1985. Transient water stress in carnation flowers: effect of amino-oxyacetic acid. J. Exp. Bot. 36:800-806.

McCabe, M.S., L.C. Garratt, F. Schepers, W.J.R.M. Jordi, G.M. Stoopen, E. Davelaar, J.H.A. van Rhijn, J.B. Power, and M.R. Davey. 2001. Effects of $\mathrm{P}_{\mathrm{SAG} 12}-\mathrm{IPT}$ Gene Expression on Development and Senescence in Transgenic Lettuce. Plant Physiol. 127:505-516.

Mills, H.A. and J.B. Jones, Jr. 1996. Plant Analysis Handbook II. MacroMicro, Athens, GA.

Mor, Y., M.S. Reid, and A.M. Kofranek, 1980. Role of the ovary in carnation senescence. Scientia Hort. 13:377-383. 
Mor, Y., H. Spiegelstein, and A.H. Halevy. 1983. Inhibition of ethylene biosynthesis in carnation petals by cytokinin. Plant Physiol. 71:541-546.

Mothes, K., and Engelbrecht. 1961. Kinetin-induced directed transport of substances in excised leaves in the dark. Phytochemistry. 1:58-62.

Nichols, R. 1966. Ethylene production during senescence of flowers. J. Hort. Sci. 41:279-290.

Nichols, R. 1973. Senescence of the cut carnation flower: respiration and sugar status. J. Hort. Sci. 48:111-121.

Nooden, L.D. and A.C. Leopold. 1988. Senescence and Aging in Plants. Academic Press. New York, N.Y.

Oertli, J.J. and H.C. Kohl, Jr. 1960. Der Einfluss der Bestaubung auf die stoffbewegung in Cymbidiumbluten. Garkenbauwissenschaft. 25:107-114.

Oh, S.A., J-H. Park, G.I. Lee, K.H. Paek, S.K. Park, and G.N. Hong. 1997. Identification of three genetic loci controlling leaf senescence in Arabidopsis thaliana. Plant J. 12:527-535.

O’Neill, S.D., J.A. Nadeau, X.S. Zhang, A.Q. Bui, and A.H. Halevy. 1993. Interorgan regulation of ethylene biosynthetic genes by pollination. Plant Cell. 5:419-432.

Panavas, T., A. Pikula, P.D. Reid, B. Rubinstein, and E.L. Walker. 1999. Identification of senescence-associated genes from daylily petals. Plant Mol. Biol. 40:237-248.

Panavas, T., E.L. Walker, and B. Rubinstein. 1998. Possible involvement of abscisic acid in senescence of daylily petals. J. Exp. Bot. 49:1987-1997.

Pandey, S., S.B. Tiwari, K.C. Upadhyaya, and S.K. Sopory. 2000. Calcium signaling: linking environmental signals to cellular functions. Crit. Rev. Plant Sci. 19(4):291-318.

Patrick, J.W., W. Zhang, S.D. Tyerman, C.O. Offler, and N.A. Walker. 2001. Role of membrane transport in phloem translocation of assimilates and water. Aust. J. Plant Physiol. 28:695707.

Picchioni, G.A., M. Valenzuela-Vasquez, and S. Armenta-Sanchez. 2001. Calcium-activated root growth and mineral nutrient accumulation of Lupinus havardii: Ecophysical and horticultural significance. J. Amer. Soc. Hort. Sci. 126:631-637.

Phillips, D.A., and C.F. Cleland. 1972. Cytokinin activity from the phloem sap of Xanthium strumarium L. Planta. 102:173-178.

Reid, M.S. 1987. Ethylene in plant growth, development, and senescence, p.257-279. In: P.J. Davies (ed.) Plant hormones and their role in plant growth and development. Marinuss Nijhoff, Den Hague.

Reid, M.S. 1989. The role of ethylene in flower senescence. Acta Hortic. 261:157-169.

Reid, M.S. and M. Wu. 1992. Ethylene and flower senescence. Plant Growth Regulation. 11:3743.

Richmond, A.E., and A. Lang. 1957. Effect of kinetin on protein content and survival of detached Xanthium leaves. Science. 125: 650-651.

Ronen, M. and S. Mayak. 1981. Interrelationship between abscisic acid and ethylene in control of senescence processes in carnation flowers. J. Exp. Bot. 32:759-765.

Rubinstein, B. 2000. Regulation of cell death in flower petals. Plant. Mol. Biol. 44:303-318.

Saha, S., P.K. Nagar, P.K. Sircar. 1985. Changes in cytokinin activity during flower development of Cosmos sulfureus Cav. Plant Growth Regulation 3:27-35.

Short, K.C. and J.G. Torrey. 1972. Cytokinins in seedling roots of pea. Plant Physiol. 49:155-160.

Singh, A., K.B. Evensen, T.H. Kao. 1992. Ethylene synthesis and floral senescence following compatible and incompatible pollinations in Petunia inflata. Plant Physiol. 99:38-45.

Smart, C.M. 1994. Gene expression during leaf senescence. New Phytol. 126:419-448.

Solomos, T. 1988. Respiration in senescing plant organs: its nature, regulation, and physiological significance, p. 111-145. In: L.D. Nooden and A.C. Leopold (ed.). Senescence and aging in plants. Academic Press, New York, N.Y.

Sparnaaij, L.D. 1976. Activities in floriculture plant breeding and genetics in The Netherlands. Acta Hortic. 63:27-36. 
Stead, A.D. 1992. Pollination-induced flower senescence: A review. Plant Growth Regulation. 11:13-20.

Stead, A.D. and K.G. Moore. 1979. Studies on flower longevity in Digitalis. Pollination-induced corolla abscission in Digitalis flowers. Planta. 146:409-414.

Sun, G., D.L. Dilcher, S. Zheng, and Z. Zhou. 1998. In search of the first flower: a Jurassic angiosperm, Archaefructus, from northeast China. Science. 282:1692-1696.

Suttle, J.C. and H. Kende. 1980. Ethylene action and loss of membrane integrity during petal senescence in Tradescantia. Plant Physiol. 65:1067-1072.

Tamimi, Y.N., D.T. Matsuyama, K.D. Ison-Takata, and R.T. Nakano. 1999. Distribution of nutrients in cut-flower roses and the quantities of biomass and nutrients removed during harvest. HortScience. 34:251-253.

Tang, X. and W.R. Woodson. 1996. Temporal and spatial expression of 1-aminocyclopropane-1carboxylic oxidase mRNA following pollination of immature and mature petunia flowers. Plant Physiol. 112:503-511.

Taiz, L. and E. Zeiger. 1991. Plant Physiology. Addison-Wesley, New York.

Taverner, E., D.S. Letham, J. Wang, E. Cornish, and D.A. Willcocks. 1999. Influence of ethylene on cytokinin metabolism in relation to Petunia corolla senescence. Phytochemistry. 51:341347.

Taylor, C.B., P.A. Bariola, S.B. Delcardayre, R.T. Raines, and P.J. Green. 1993. RNA2: a senescence-associated RNase of Arabidopsis that diverged from the S-RNases before speciation. Proc. Natl. Acad. Sci. USA. 90:5118-5122.

Tetley, R.M. and K.V. Thimann. 1974. The metabolism of oat leaves during senescence. I. Respiration, carbohydrate metabolism, and the action of cytokinins. Plant Physiol. 54:294303.

Turgeon, R. 1989. The sink-source transition in leaves. Ann. Rev. Plant Physiol. Plant Mol. Biol. 40:119-138.

van Doorn, W.G. 1997. Effects of pollination on floral attraction and longevity. J. Exp. Bot. 48:1615-1622.

van Doorn, W.G. P.A. Balk, A.M. van Houwelingen, F.A. Hoeberichts, R.D. Hall, O. Vorst, C. van der Schoot, M.F. van Wordragen. 2003. Gene expression during anthesis and senescence in Iris flowers. Plant Mol. Biol. 53:845-863.

van Staden, J., E. Cook, and L.D. Nooden. 1988. Cytokinins and senescence. In L.D. Nooden, A.C. Leopold, eds., Senescence and Aging in Plants. Academic Press, San Diego, pp. 281328.

van Staden, J., and J.E. Davey. 1979. The synthesis, transport and metabolism of endogenous cytokinins. Plant Cell Environ. 2:93-106.

van Staden, J. and G.G. Dimalla. 1980. The effect of silver thiosulfate preservative on the physiology of cut carnations: II. Influence of endogenous cytokinins. Z. Pflanzenphysiol. 99:19-26.

Veen, H. and A.A.M. Kwakkenbos. 1982. The effect of silver thiosulfate pre-treatment on 1aminocyclopropane-1-carboxylic acid content and action in cut carnations. Scientia Hort. 18:277-286.

Verlinden, S. 2003. Changes in mineral nutrient concentrations in petunia corollas during development and senescence. HortScience. 38(1):71-74.

Wehmer, C. 1900. Ueber einen Fall intensiver Schaedigung einer Alee durch ausstroemendes Leuchtgas. Zeitschr. Pflanzenkr. 10:267-269.

Weiss, C., and Y. Vadia. 1965. Kinetin-like activity in root apices of sunflower plants. Life Sci. 4:1323-1326.

Whitehead, C.S. 1994. Ethylene sensitivity and flower senescence, p. 269-284. In: R.J. Scott and A.D. Stead (eds.). Molecular and cellular aspects of plant reproduction (Society for experimental biology seminar series, vol. 55). Cambridge University Press. 
Whitehead, C.S., A.H. Halevy, and M.S. Reid. 1984. Roles of ethylene and 1aminocyclopropane-1-carboxylic acid in pollination and wound-induced senescence of Petunia hybrida flowers. Physiol. Plant. 61:643-648.

Winkenbach, F., and Ph. Matile. 1970. Evidence for de novo synthesis of an invertase inhibitor protein in senescing petals of Ipomoea. Z. Pflanzenphysiol. 63:292-295.

Wilkinson, J.Q., M.B. Lanahan, D.G. Clark, A.B. Bleecker, C. Chang, E.M. Meyerowitz, and H.J. Klee. 1997. A dominant mutant receptor from Arabidopsis confers ethylene insensitivity in heterologous plants. Nature Biotechnology. 15:444-447.

Wilson, C.M. 1982. Plant nucleases: biochemistry and development of multiple molecular forms, p. 33-54. In: M.C. Rattazzi, J.G. Scandalios, G.S. Whitt (eds.). Isozymes: Current topics in biological and medical research, Vol. 6. Alan R. Liss, New York, N.Y.

Woltering, E.J. and W.G. Van Doorn. 1988. Role of ethylene in senescence of petals morphological and taxonomical relationships. J. Exp. Bot. 39:1605-1616.

Woodson, W.R. and A.K. Handa. 1987. Changes in protein patterns and in vivo protein synthesis during presenescence and senescence of hibiscus petals. J. Plant Physiol. 128:67-75.

Woodson, W.R., K.Y. Park, A. Drory, P.B. Larsen, and H. Wang. 1992. Expression of ethylene biosynthetic pathway transcripts in senescing carnation flowers. Plant Physiol. 99:526-532.

Woodson, W.R. 1994. Molecular biology of flower senescence in carnation, p. 255-267. In: R.J. Scott and A.D. Stead (eds.). Molecular and cellular aspects of plant reproduction (Society for experimental biology seminar series, vol. 55). Cambridge University Press.

Wulster, G., J. Sacalis, and H. Janes. 1982. The effect of inhibitors of protein synthesis on ethylene-induced senescence in isolated carnation petals. J. Am. Soc. Hort. Sci. 107:112115.

Xu, Y. and M.R. Hanson. 2000. Programmed cell death during pollination-induced petal senescence in Petunia. Plant Physiol. 122:1323-1333.

Yang, S.F., N.E. Hoffman. 1984. Ethylene biosynthesis and its regulation in higher plants. Annu. Rev. Plant Physiol. 35:155-189.

Zarembinski, T., and A. Theologis. 1994. Ethylene biosynthesis and action: a case of conservation. Plant Mol. Biol. 26:1579-1597. 